\title{
Photochemical degradation of isoprene-derived 4,1-nitrooxy enal
}

\author{
Fulizi Xiong ${ }^{1}$, Carlos H. Borca ${ }^{1}$, Lyudmila V. Slipchenko ${ }^{1}$, and Paul B. Shepson ${ }^{1,2}$ \\ ${ }^{1}$ Department of Chemistry, Purdue University, West Lafayette, IN, USA \\ ${ }^{2}$ Department of Earth, Atmospheric and Planetary Sciences, Purdue University, West Lafayette, IN, USA
}

Correspondence to: Paul B. Shepson (pshepson@ purdue.edu)

Received: 24 January 2016 - Published in Atmos. Chem. Phys. Discuss.: 8 February 2016

Revised: 18 April 2016 - Accepted: 25 April 2016 - Published: 4 May 2016

\begin{abstract}
In isoprene-impacted environments, carbonyl nitrates are produced from $\mathrm{NO}_{3}$-initiated isoprene oxidation, which constitutes a potentially important $\mathrm{NO}_{x}$ reservoir. To better understand the fate of isoprene carbonyl nitrates, we synthesized a model compound, trans-2methyl-4-nitrooxy-2-buten-1-al (4,1-isoprene carbonyl nitrate, or 4,1-isoprene nitrooxy enal), and investigated its photochemical degradation process. The measured $\mathrm{OH}$ and $\mathrm{O}_{3}$ oxidation rate constants $(298 \mathrm{~K})$ for this nitrooxy enal are $4.1( \pm 0.7) \times 10^{-11} \mathrm{~cm}^{3}$ molecules ${ }^{-1} \mathrm{~s}^{-1}$ and $4.4( \pm 0.3) \times 10^{-18} \mathrm{~cm}^{3}$ molecules ${ }^{-1} \mathrm{~s}^{-1}$, respectively. Its UV absorption spectrum was determined, and the result is consistent with TDDFT calculations. Based on its UV absorption cross section and photolysis frequency in a reaction chamber, we estimate that the ambient photolysis frequency for this compound is $3.1( \pm 0.8) \times 10^{-4} \mathrm{~s}^{-1}$ for a solar zenith angle of $45^{\circ}$. The fast photolysis rate and high reactivity toward $\mathrm{OH}$ lead to a lifetime of less than $1 \mathrm{~h}$ for the isoprene nitrooxy enal, with photolysis being a dominant daytime sink. The nitrate products derived from the $\mathrm{OH}$ oxidation and the photolysis of the nitrooxy enal were identified with an iodide-based chemical ionization mass spectrometer. For the $\mathrm{OH}$ oxidation reaction, we quantified the yields of two nitrate products, methyl vinyl ketone nitrate and ethanal nitrate, which together contributed to $36( \pm 5) \%$ of the firstgeneration products.
\end{abstract}

\section{Introduction}

Over the past century, tropospheric background ozone concentrations have increased from $\sim 20$ to $\sim 40 \mathrm{ppb}$, with urban-impacted concentrations often rising to $60-100 \mathrm{ppb}$ (Parrish et al., 2014; Vingarzan, 2004), posing harmful ef- fects on human health and crop yields (Lefohn and Foley, 1993; Lippmann, 1989). Tropospheric ozone is catalytically produced in the chemical reactions of nitrogen oxides $\left(\mathrm{NO}_{x} \equiv \mathrm{NO}+\mathrm{NO}_{2}\right)$ and volatile organic compounds (VOCs) (Haagen-Smit, 1952). $\mathrm{NO}_{2}$ photolysis forms ozone (Blacet, 1952), and the ozone production rate is enhanced when the $\mathrm{NO}-\mathrm{NO}_{2}-\mathrm{O}_{3}$ cycle is coupled with the oxidation of VOCs (Chameides et al., 1988, 1992; Chameides and Walker, 1973). When $\mathrm{NO}_{x}$ is incorporated into organic molecules and forms organic nitrates $\left(\mathrm{RONO}_{2}\right)$, however, ozone formation is suppressed (Roberts, 1990). Organic nitrates are a temporary $\mathrm{NO}_{x}$ reservoir. Degradation of organic nitrates can release $\mathrm{NO}_{2}$ back into the atmosphere (Aschmann et al., 2011) and thus facilitate ozone production. Organic nitrates in the gas phase can also adsorb onto atmospheric aerosols, followed by condensed-phase hydrolysis (Rindelaub et al., 2015). This process removes the reactive nitrogen from the atmosphere permanently, as the nitrooxy group is converted into the nonvolatile $\mathrm{NO}_{3}^{-}$ion (Darer et al., 2011; Hu et al., 2011). The relative importance of these parallel nitrate sinks affects the availability of $\mathrm{NO}_{x}$ and the ozone production rate in the troposphere. Therefore, detailed understanding of the loss mechanisms of organic nitrates is crucial to understanding the dynamics of ground-level ozone formation.

Modeling studies suggest that isoprene-derived organic nitrates have substantial influence on the $\mathrm{NO}_{x}$ cycle and tropospheric $\mathrm{O}_{3}$ production (Horowitz et al., 2007; Mao et al., 2013; Paulot et al., 2012; Wu et al., 2007). During the daytime, isoprene is lost rapidly to $\mathrm{OH}$ oxidation, forming organic nitrates through the $\mathrm{RO}_{2}+\mathrm{NO}$ reaction, with a yield of 7-14\% (Lockwood et al., 2010; Patchen et al., 2007; Paulot et al., 2009; Sprengnether et al., 2002; Tuazon and Atkinson, 1990; Xiong et al., 2015). At night, reaction with $\mathrm{NO}_{3}$ is a significant removal pathway for isoprene (Brown et al., 2009; 


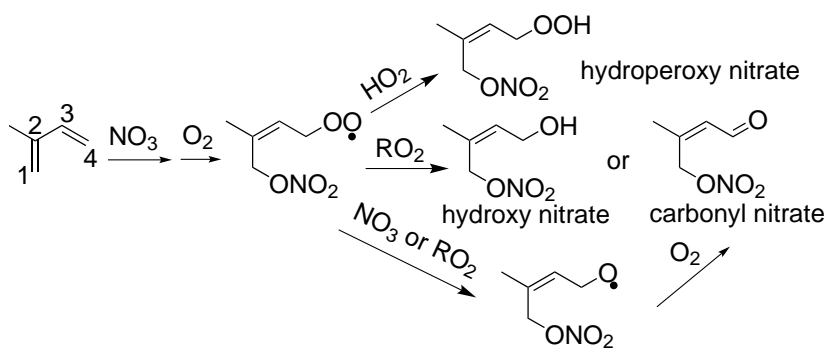

Figure 1. Organic nitrates produced from $\mathrm{NO}_{3}$-initiated isoprene oxidation.

Starn et al., 1998), and organic nitrates constitute $65-70 \%$ of the oxidation products (Perring et al., 2009; Rollins et al., 2009). While $\mathrm{NO}_{3}$-initiated isoprene oxidation contributes to a small fraction of isoprene loss, this reaction pathway could generate approximately half of the isoprene-derived organic nitrates on a regional scale due to its large nitrate yield (Horowitz et al., 2007; Xie et al., 2013).

Figure 1 shows the formation pathways of organic nitrate products from $\mathrm{NO}_{3}$-initiated oxidation of isoprene, including hydroperoxy nitrate, carbonyl nitrate, and hydroxy nitrate. Reactions for only one of the nitrooxy peroxy radicals are shown for brevity. The hydroxy nitrates can be also formed in the $\mathrm{OH}$-initiated isoprene oxidation reactions, and their production and degradation have been studied extensively in both laboratory and field studies (Chen et al., 1998; Giacopelli et al., 2005; Grossenbacher et al., 2004; Jacobs et al., 2014; Lee et al., 2014b; Lockwood et al., 2010; Patchen et al., 2007; Paulot et al., 2009; Sprengnether et al., 2002; Tuazon and Atkinson, 1990; Xiong et al., 2015). For the hydroperoxy nitrates, Schwantes et al. (2015) investigated their production from the $\mathrm{RO}_{2}+\mathrm{HO}_{2}$ reaction and identified the nitrooxy hydroxy epoxide product from the $\mathrm{OH}$ oxidation of the isoprene hydroperoxy nitrate. For the isoprene carbonyl nitrates, their formation has been quantified in an experimental study (Kwan et al., 2012), but their sinks and fate can only be inferred from analog molecules, such as nitrooxy ketones, due to lack of direct studies on these specific compounds. Suarez-Bertoa et al. (2012) conducted kinetics experiments on three synthesized saturated nitrooxy ketones, and their results indicate that photolysis is the dominant sink for these nitrate compounds. By comparing the published UV absorption spectra of $\alpha$-nitrooxy ketones with the UV spectra of the mono-functional nitrates and ketones, Müller et al. (2014) suggested that the nitrooxy ketones have enhanced absorption cross sections, due to the interaction between the $-\mathrm{C}=\mathrm{O}$ and the $-\mathrm{ONO}_{2}$ chromophores. In addition, near-unit photolysis quantum yields for $\alpha$-nitrooxy acetone and 3-nitrooxy2-butanone were inferred by Müller et al. (2014), based on the photolysis frequencies determined by Suarez-Bertoa et al. (2012) and known absorption cross sections (Barnes et al., 1993). The enhanced absorption cross sections and quantum yields of carbonyl nitrates resulting from chromophore

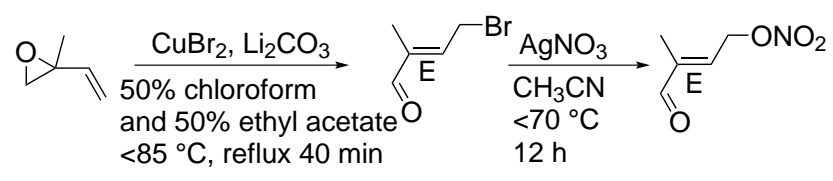

Figure 2. The synthesis route for the 4,1-isoprene nitrooxy enal.

interactions lead to fast photolysis rates that are more consistent with the loss rates constrained by the measured temporal profiles of carbonyl nitrates in an isoprene oxidation experiment performed by Paulot et al. (2009; Müller et al., 2014). Like the carbonyl nitrates discussed by Suarez-Bertoa et al. (2012) and Müller et al. (2014), some of the carbonyl nitrate isomers derived from $\mathrm{NO}_{3}+$ isoprene oxidation have a conjugated chromophore, $-\mathrm{C}=\mathrm{C}-\mathrm{C}=\mathrm{O}$ (enal), at the $\beta$ position of the nitrate group, which may enhance the UV absorption cross section of the molecule and facilitate its photolytic dissociation. However, since the five-carbon isoprene carbonyl nitrate (nitrooxy enal) (Fig. 1) is unsaturated, it is also expected to be lost rapidly to $\mathrm{OH}$ oxidation. To date, the relative importance of the individual photochemical sinks for the unsaturated carbonyl nitrates is still unclear. To answer this question, we synthesized a model compound for the fivecarbon isoprene carbonyl nitrates and investigated its photochemical reactivities and fate.

\section{Synthesis and characterization}

A model compound, trans-2-methyl-4-nitrooxy-2-buten-1-al (4,1-isoprene nitrooxy enal) was synthesized following the reaction scheme in Fig. 2. The nitrate was prepared by reacting $\mathrm{AgNO}_{3}$ with the corresponding bromide (trans-4-bromo2-methyl-2-buten-1-al) (Ferris et al., 1953), which was synthesized following Gray (1981). The ${ }^{1} \mathrm{H}$ and ${ }^{13} \mathrm{C}$ nuclear magnetic resonance (NMR) spectra of the synthesized product are shown in Figs. S1 and S2 in the Supplement. Its IR absorption spectrum is shown in Fig. S3.

Shown in Fig. 3 are the UV absorption cross sections for the nitrooxy enal, methacrolein (MACR), and isopropyl nitrate. Each spectrum was obtained using a solution that contained one single pure analyte in acetonitrile solvent. Only solution-phase spectra were determined, because gas-phase cells may have potential wall loss problems and thus the quantitative gas-phase cross sections are difficult to measure. We compared isopropyl nitrate and MACR with isoprene nitrooxy enal, because MACR has the enal structure, isopropyl nitrate has the nitrooxy group, and the combination of these two compounds helps to illustrate the absorption features of the nitrooxy enal studied in this work. The absorption cross section of the carbonyl nitrate is enhanced relative to that of MACR, but the two spectra have similar features from 320 to $400 \mathrm{~nm}$ with peak absorption at $325 \mathrm{~nm}$. This is probably because they both contain the $\mathrm{O}=\mathrm{C}-\mathrm{C}=\mathrm{C}$ chromophore. Below $320 \mathrm{~nm}$ the absorption of the nitrooxy enal is enhanced 


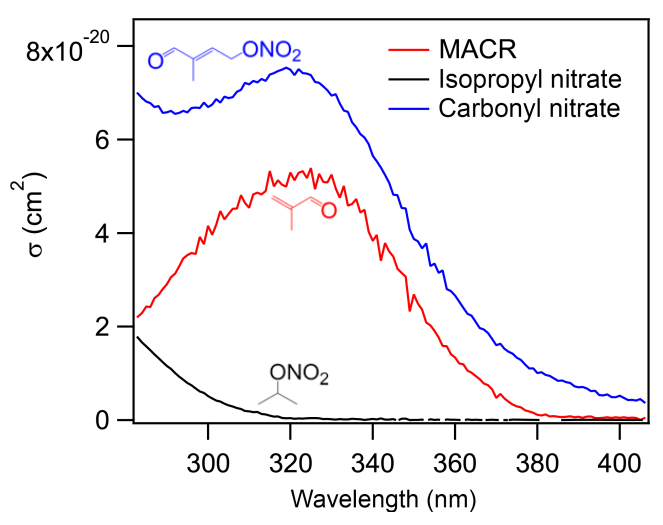

Figure 3. UV absorption cross section of the nitrooxy enal, MACR, and isopropyl nitrate. The spectra were all obtained in acetonitrile solvent.

significantly in comparison with that of isopropyl nitrate. This observation is consistent with reports from Müller et al. (2014) that molecules containing $\alpha, \beta$-nitrooxy ketone functionalities have enhanced UV absorption.

\section{Methods}

\subsection{Setup for the kinetics chamber experiments}

Three sets of reaction chamber experiments were conducted to determine the photolysis frequency, $\mathrm{OH}$ oxidation rate constant, and the $\mathrm{O}_{3}$ oxidation rate constant for the isoprene nitrooxy enal. Since this work is focused on the photochemistry of the nitrooxy enal, which describes the loss-dominant processes after sunrise, we did not include experiments concerning the $\mathrm{NO}_{3}$-initiated oxidation processes for this compound. The experiments were performed in the $5500 \mathrm{~L}$ Purdue photochemical reaction chamber (Chen et al., 1998). A chemical ionization mass spectrometer (CIMS) with $\mathrm{I}^{-}$as the reagent ion (Xiong et al., 2015) was used to quantify the nitrooxy enal (observed at nominal mass $m / z 272$ ) and its nitrate degradation products. The CIMS has unit mass resolution. Since pure isoprene nitrooxy enal was introduced into the reaction as the precursor, we do not expect significant interference from the isotope signal of $m / z 271$. The chamber air was sampled into the CIMS through $5.2 \mathrm{~m}$ long FEP tubing $\left(0.8 \mathrm{~cm} \mathrm{ID,} \mathrm{heated} \mathrm{to} \mathrm{constant} 50^{\circ} \mathrm{C}\right)$. The residence time for the sampling tubing was approximately $5 \mathrm{~s}$, and laminar flow was maintained. To assess the influence of the heated inlet on the stability of the nitrooxy enal, we have sampled the nitrooxy enal using the heated $50^{\circ} \mathrm{C}$ inlet and using a $20 \mathrm{~cm}$ room temperature inlet, and there was no significant difference in their corresponding CIMS signals. In addition, the trans-isoprene nitrooxy enal was synthesized in an oil bath maintained at $70^{\circ} \mathrm{C}$, but the formation of the cis isomer was not observed. Therefore, we do not consider that there is significant thermal isomerization inside our sampling

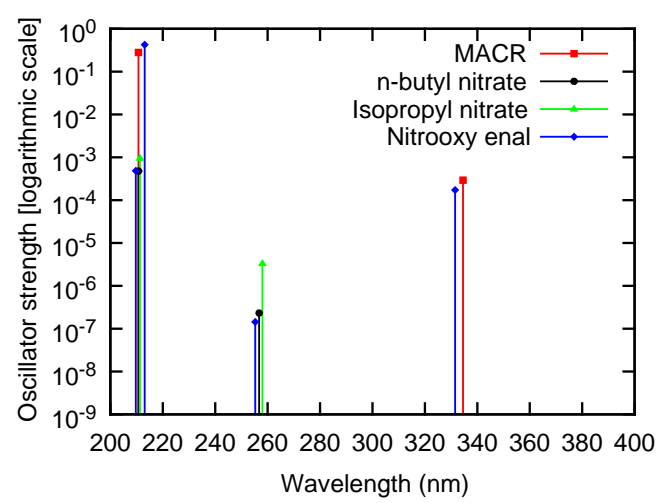

Figure 4. Theoretical gas-phase absorption spectra of the nitrooxy enal, MACR, isopropyl nitrate, and $n$-butyl nitrate in the gas phase.

line. The photolysis frequency was obtained by measuring the loss of the nitrooxy enal inside the reaction chamber in the presence of UV radiation and propene as a radical scavenger. When the UV lamps were turned off, the wall loss rate constant for the nitrooxy enal was derived by observing its slow decay, with propene as an ozone and $\mathrm{NO}_{3}$ scavenger. The $\mathrm{OH}$ reaction rate constant and $\mathrm{O}_{3}$ reaction rate constant were obtained using the relative rate method (Atkinson and Aschmann, 1985). Propene was used as the reference compound, and its changing concentrations were measured using a gas chromatograph (GC) - flame ionization detector (FID) equipped with a $0.32 \mathrm{~mm}$ Rtx-Q-Bond column. For the $\mathrm{OH}$ oxidation experiments, $\mathrm{OH}$ was generated through the photolysis of isopropyl nitrite, which was synthesized following Noyes (1933). NO was added to the chamber to suppress the formation of $\mathrm{O}_{3}$. In addition, two $\mathrm{OH}$ oxidation experiments were performed without propene in order to quantify the oxidation products. For the $\mathrm{OH}$-initiated oxidation experiments, $\mathrm{NO}$ and $\mathrm{NO}_{2}$ were measured using the Total REactive Nitrogen Instrument (TRENI) (Lockwood et al., 2010). The ozonolysis experiments were performed in the dark, and cyclohexane was added to the chamber as an $\mathrm{OH}$ scavenger. The initial conditions for the experiments are listed in Table $\mathrm{S} 1$.

\subsection{Computational methods}

The theoretical UV absorption spectra of the isoprene nitrooxy enal, MACR, isopropyl nitrate, and $n$-butyl nitrate in the gas phase were calculated separately and analyzed, in four stages, using time-dependent density functional theory (TDDFT; Hohenberg and Kohn, 1964; Kohn and Sham, 1965; Runge and Gross, 1984). All calculations were carried out using the computational chemistry package Q-Chem 4.3 (Shao et al., 2015). First, the structure of each molecule was optimized employing the long-range corrected hybrid density functional $\omega$ B97X-D (Chai and Head-Gordon, 2008) with the $6-31+\mathrm{G}^{*}$ basis set (Frisch et al., 1984). A high-accuracy 

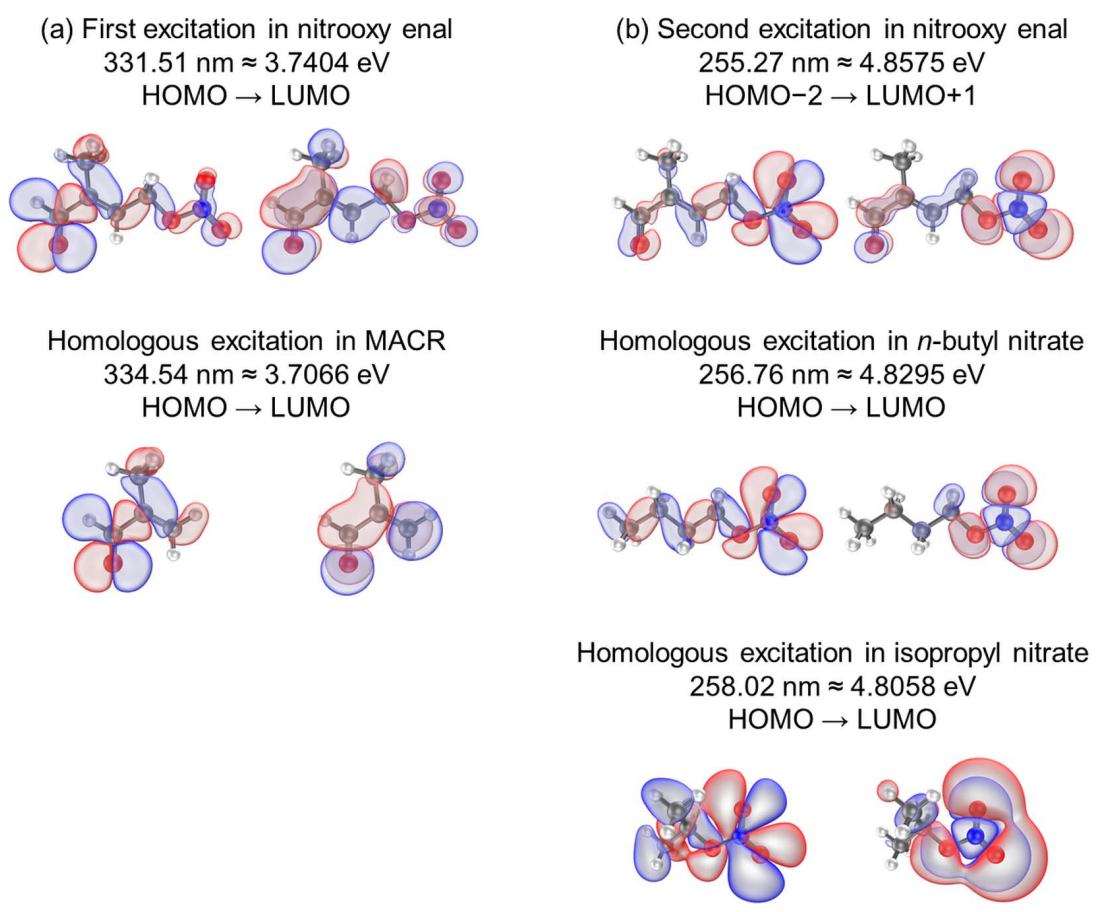

Figure 5. Molecular orbital analysis of the first (a) and second (b) electronic excitations of the nitrooxy enal, along with analogous excitations of MACR, isopropyl nitrate, and $n$-butyl nitrate. The blue and red colors represent the opposite phases of molecular orbitals.

grid was employed. Second, frequency calculations were executed on the optimized structures to verify their accuracy. These were run using the same setup described above. Third, after assuring the structures represented adequate minima, the first 10 singlet excited states of each molecule were computed with TDDFT, using the same functional and basis set. Finally, a visual analysis of the molecular orbitals (MOs) was carried out with the visualization software IQmol 2.7 (Gilbert, 2012).

\section{Results}

\subsection{Absorption spectra and density functional calculations}

Figure 4 shows the TDDFT UV absorption spectra of the nitrooxy enal, MACR, isopropyl nitrate, and $n$-butyl nitrate. There are three groups of transitions in the simulated spectra. Unlike the absorption bands depicted in Fig. 3, the theoretical gas-phase spectra in Fig. 4 are showing only the electronic transition lines. To accurately capture the broadening of these lines in TDDFT as to simulate absorption bands, we have to consider the effect of the chromophore's vibrational degrees of freedom and/or to include a condensed-phase environment that surrounds the chromophore. However, explicit modeling of broadening either due to vibronic interactions or solvent effects is computationally challenging and beyond the scope of this work. Both MACR and the nitrooxy enal show a rel- atively weak transition in the region around $330 \mathrm{~nm}$, which corresponds to the first electronic transition, from the highest occupied molecular orbital (HOMO) to the lowest unoccupied molecular orbital (LUMO), in both molecules. Figure 5 a provides comparative information between the first electronic transition of the nitrooxy enal and the homologous excitation of MACR. As shown in Fig. 5a the character of the molecular orbitals involved in this transition is similar in both cases, indicating that the aldehyde group is involved in the first electronic excitation of the nitrooxy enal.

Figure $5 \mathrm{~b}$ shows the information corresponding to the second electronic transition of the nitrooxy enal and its homologous excitation in isopropyl nitrate and $n$-butyl nitrate. These three transitions are found in the region around $255 \mathrm{~nm}$. The second electronic transition of the nitrooxy enal is 3 orders of magnitude weaker than its first excitation, located at $330 \mathrm{~nm}$. Inspection of the character of the MOs involved in these processes reveals a correspondence between the second electronic excitation of the nitrooxy enal, $\mathrm{HOMO}-2 \rightarrow \mathrm{LUMO}+1$, and the HOMO $\rightarrow$ LUMO transitions in both isopropyl nitrate and $n$-butyl nitrate. As with the previous case, that observation confirms that the nitrate group is involved in the second electronic excitation of the nitrooxy enal. Figure $5 \mathrm{~b}$ also shows that in this case, the local character of the MOs involved in the transition is even more pronounced, with bulky lobes placed mainly over the nitrate group. 
Even though the second electronic transition of carbonyl nitrate is not displayed in the experimental spectra of Fig. 3, because its range covers from 280 to $410 \mathrm{~nm}$, it is reasonable to assume that it is caused by the local excitation of the nitrate group, based on the computational results. Thus, it can be suggested that the experimental UV absorption spectrum of isopropyl nitrate is comparable to those of isopropyl nitrate and $n$-butyl nitrate simulated computationally. Thus it is possible that the feature in the region around $280 \mathrm{~nm}$ of the nitrooxy enal experimental spectrum in Fig. 3 could be caused by a broadening of the transition located around $255 \mathrm{~nm}$.

Another plausible explanation of the feature around $280 \mathrm{~nm}$ for the nitrooxy enal would be a broadening of its brightest transition in the modeled spectrum. It is located around $210 \mathrm{~nm}$, and it is 3 orders of magnitude brighter than the one at $330 \mathrm{~nm}$. In that region, there are two transitions and each one has a homologous excitation: the HOMO $-1 \rightarrow$ LUMO in nitrooxy enal is similar to $\mathrm{HOMO}-1 \rightarrow \mathrm{LUMO}$ in MACR, and the $\mathrm{HOMO}-5 \rightarrow \mathrm{LUMO}+1$ in nitrooxy enal is related to the (mainly) HOMO $-1 \rightarrow$ LUMO transitions of isopropyl nitrate and $n$-butyl nitrate. These transitions are beyond the range of the experimental spectra on Fig. 3 and beyond the atmospherically relevant absorption wavelengths. The theoretical calculations suggest that the nitrooxy group has electronic transitions at 210 and $255 \mathrm{~nm}$, but both wavelengths are outside the solar radiation spectrum near the ground. Therefore, we speculate that the isoprene nitrooxy enal absorbs photons primarily through the first electronic transition concerning the enal chromophore, instead of the nitrooxy functionality, and the dissociation of the $\mathrm{O}-\mathrm{NO}_{2}$ bond (Sect. 4.3.2) likely results from intramolecular energy redistribution.

\subsection{Photochemical sinks of the 4,1-isoprene nitrooxy enal}

Figure 6 shows the first-order wall loss and photolysis loss of the nitrooxy enal inside the reaction chamber. The wall loss rate constant was $1.3( \pm 0.2) \times 10^{-5} \mathrm{~s}^{-1}(95 \%$ confidence interval), and the photolysis rate constant was $3.0( \pm 0.2) \times 10^{-5} \mathrm{~s}^{-1}(95 \%)$, after subtracting the wall loss rate constant from the first-order decay rate constant measured for the photolysis experiments. The radiation intensity inside the chamber is approximately $10 \%$ of solar radiation. Therefore, our photolysis rate constant is small, making the wall loss rate constant significant, compared with the photolysis frequency. It is worth mentioning that our reactant nitrooxy enal has a trans configuration, and it may photoisomerize into the cis configuration, which would be detected at the same $m / z$ by the CIMS. The cis-nitrooxy enal can either photo-dissociate or isomerize to re-form the trans isomer. Our previous work suggests that the CIMS is 4 times more sensitive to the cis configuration than the trans configuration (Xiong et al., 2015). If the lifetime for the trans $\rightarrow$ cis

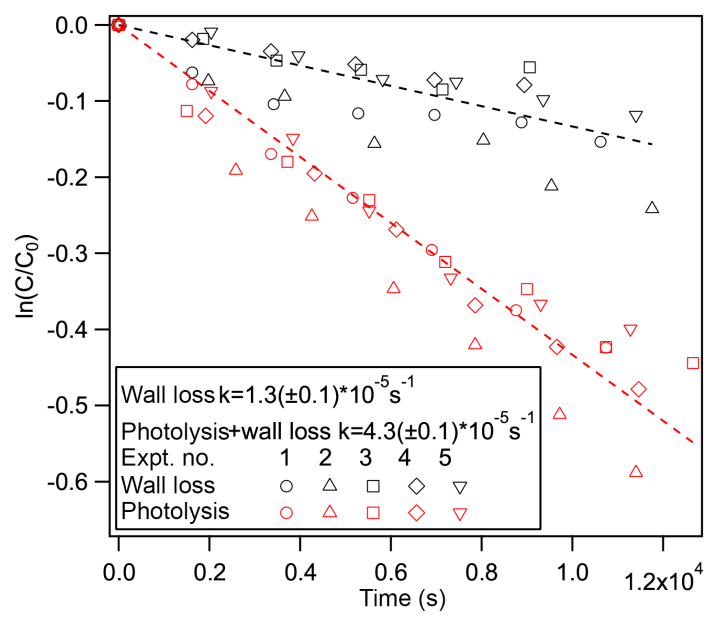

Figure 6. Wall loss and photolysis loss of the nitrooxy enal in the reaction chamber.

reaction is comparable to the duration of the experiments (approximately $3 \mathrm{~h}$ ), we would expect the CIMS signal to resemble a double exponential curve, because the cis isomer was being produced and consumed simultaneously. This double exponential curve is not observed for the photolysis data (Fig. 6). If a cis-trans equilibrium is established instantaneously, the CIMS signal would still be a single exponential curve, which represents the loss of both isomers. However, given the similar nitrooxy enal structures for the $c i s$ and trans isomers, we do not expect their photolysis frequencies to differ significantly, so the total photolysis rate constant obtained from the CIMS measurement can be used as the photolysis frequency for the individual cis or trans isomer. Therefore, regardless of the trans $\rightarrow$ cis isomerization rate, our measured photolysis frequency should characterize well the loss rate of the precursor trans-nitrooxy enal inside the reaction chamber.

Since the UV radiation inside the reaction chamber is different from the UV radiation in the ambient environment (Fig. 7), $\mathrm{Cl}_{2}$ was used as a reference compound to translate the nitrate photolysis rate from chamber radiation to solar radiation. The photolysis decay of $\mathrm{Cl}_{2}$ in the reaction chamber was measured with the CIMS (Neuman et al., 2010). Cyclohexane was added to the chamber to scavenge the $\mathrm{Cl}$ atoms so that $\mathrm{Cl}_{2}$ was not re-formed from $\mathrm{Cl}+\mathrm{Cl}$ recombination. The first-order photolysis rate constant for $\mathrm{Cl}_{2}$ was $2.50( \pm 0.08) \times 10^{-4} \mathrm{~s}^{-1}$ (Fig. S4).

The photolysis frequency $(J)$ is the integrated product of quantum yield $(\Phi)$, absorption cross section $\left(\sigma, \mathrm{cm}^{2}\right)$ and actinic flux $\left(F, \mathrm{~cm}^{-2} \mathrm{~s}^{-1}\right)$ across all wavelengths (Eq. 1). Therefore, the photolysis frequencies for the nitrooxy enal and $\mathrm{Cl}_{2}$ in the reaction chamber can be compared as in Eq. (2).

$J=\int \Phi_{\lambda} \sigma_{\lambda} F_{\lambda} \mathrm{d} \lambda$ 


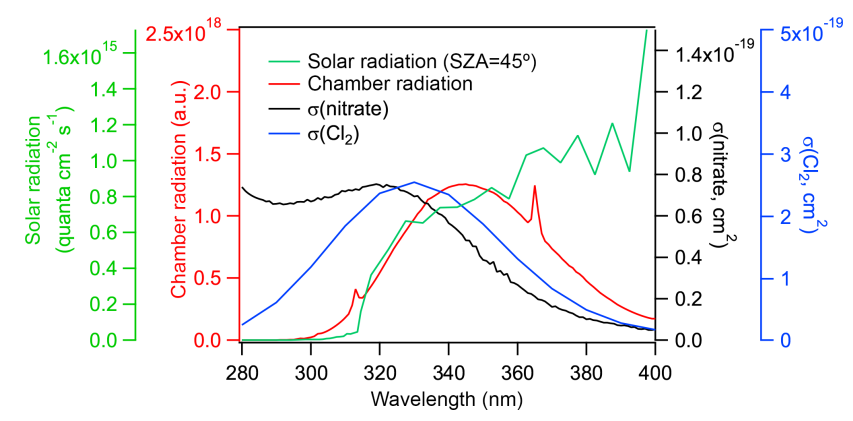

Figure 7. The radiation spectra of the chamber (red) and the sun (green, $\mathrm{SZA}=45^{\circ}$ as an example), and the absorption spectra of the nitrooxy enal (black, obtained in the liquid phase using acetonitrile solvent) and chlorine (blue).

$\frac{J_{\mathrm{Cl}_{2}}^{\text {chamber }}}{J_{\text {nitrate }}^{\text {chamber }}}=\frac{\sum \varphi_{\mathrm{Cl}_{2}} \sigma_{\mathrm{Cl}_{2}} F_{\text {chamber }}}{\sum \varphi_{\text {nitrate }} \sigma_{\text {nitrate }} F_{\text {chamber }}}$

$J_{\mathrm{Cl}_{2}}^{\text {chamber }}$ and $J_{\text {nitrate }}^{\text {chamber }}$ are the photolysis frequencies of $\mathrm{Cl}_{2}$ and the nitrooxy enal inside the chamber. $\sigma_{\mathrm{Cl}_{2}}$ and $\sigma_{\text {nitrate }}$ are the cross sections for $\mathrm{Cl}_{2}$ and the nitrooxy enal at each wavelength. $\sigma_{\text {nitrate }}$ was determined by this work (Fig. 3). $\sigma_{\mathrm{Cl}_{2}}$ has been measured previously and the IUPAC recommended values were used (Atkinson et al., 2007). $F_{\text {chamber }}$ is the wavelength-dependent flux of photons inside the chamber. The radiation spectrum (Fig. 7) of the chamber UV lamps (UVA 340) was obtained from the manufacturer (Q-lab), but the actual absolute radiation intensity in the chamber is expected to differ from the manufacturer's radiation spectrum by a scaling factor, because of the inverse-square dependence on distance, and our specific multi-lamp geometry. When $\mathrm{Cl}_{2}$ was used as a reference compound for the nitrate photolysis rate, the scaling factors in Eq. (2) will cancel.

The $\mathrm{Cl}-\mathrm{Cl}$ bond dissociation energy is $243 \mathrm{~kJ} \mathrm{~mol}^{-1}$ (Luo, 2007b), equivalent to a photon at $492 \mathrm{~nm}$. Since $\mathrm{Cl}_{2}$ has only one bond, it has unity quantum yield below $492 \mathrm{~nm}$ and zero quantum yield above $492 \mathrm{~nm}$. The emission spectrum of the UV lamps for the reaction chamber is centered from 300 to $400 \mathrm{~nm}$ (Fig. 7). Hence, $\varphi_{\mathrm{Cl}_{2}}=1$ in Eq. (2), at all wavelengths. For the nitrooxy enal, however, its quantum yield is affected by the bond dissociation energy, intramolecular vibrational energy redistribution, and relaxation of the excited molecule from collisions, so an average effective quantum yield $\left(\varphi_{\text {nitrate }}^{\text {eff }}\right)$ is assumed, and Eq. (2) becomes Eq. (3). Since the photolysis rates, absorption cross sections and chamber radiation spectrum are known, we calculate that $\varphi_{\text {nitrate }}^{\text {eff }}$ was 0.48 .

$\frac{J_{\mathrm{Cl}_{2}}^{\text {chamber }}}{J_{\text {nitrate }}^{\text {chamber }}}=\frac{\sum \sigma_{\mathrm{Cl}_{2}} F_{\text {chamber }}}{\varphi_{\text {nitrate }}^{\text {eff }} \sum \sigma_{\text {nitrate }} F_{\text {chamber }}}$

The effective quantum yield of 0.48 indicates that when the nitrooxy enal absorbs a photon inside the reaction chamber, the probability (averaged across the absorption wavelengths) for it to dissociate is $48 \%$. However, the probability for nitrate photolysis is not equal at all wavelengths, the low energy photons (long wavelength) being less likely to induce photo-dissociation. Hence, we introduce a threshold wavelength $\lambda_{0}$, for which the nitrooxy enal has unity quantum yield below $\lambda_{0}$ and zero quantum yield above $\lambda_{0}$. Although this approach accounts for the energy difference of photons with different wavelengths, it is still a very rough estimation. Using the threshold wavelength, the effective quantum yield can be expressed by Eqs. (4) and (5), where $\varphi(\lambda)$ is the quantum yield of the nitrooxy enal, and $F(\lambda)$ is the chamber photon flux (Fig. 7), as a function of the wavelength $\lambda$. Solving for the unknown $\lambda_{0}$ in Eq. (5), we calculate that $\lambda_{0}$ should be $347 \mathrm{~nm}$.

$\varphi(\lambda)=\left\{\begin{array}{l}1\left(\lambda \leq \lambda_{0}\right) \\ 0\left(\lambda>\lambda_{0}\right)\end{array}\right.$

$\frac{\sum_{\lambda} F(\lambda) \cdot \varphi(\lambda)}{\sum_{\lambda} F(\lambda)}=0.48$

The solar radiation spectrum was calculated with the TUV model (Madronich and Flocke, 1998). By assuming that the nitrooxy enal has zero quantum yield above $347 \mathrm{~nm}$ and unity quantum yield below $347 \mathrm{~nm}$, its photolysis frequency is $2.6 \times 10^{-4} \mathrm{~s}^{-1}$ for a solar zenith angle (SZA) of $45^{\circ}$ and $3.7 \times 10^{-4} \mathrm{~s}^{-1}$ for SZA of $0^{\circ}$. It is worth mentioning that the condensed-phase and gas-phase absorption spectra should be different, because the solvent molecules affect the polarization and dipole moment of the solute (Bayliss and McRae, 1954; Braun et al., 1991; Linder and Abdulnur, 1971). Although we were unable to measure the gas-phase cross section of the nitrooxy enal, we could assess the uncertainty caused by using the condensed-phase spectrum in our calculation, by comparing the gas-phase and condensed-phase spectra of MACR and isopropyl nitrate (Fig. S5a). On average, the gas-phase absorption cross sections of MACR and isopropyl nitrate are 1.7 times those in the solution phase (Fig. S5b), calculated as the ratio of the gas-phase cross sections divided by the condensed-phase cross sections at each wavelength. For the nitrooxy enal, if the gasphase cross section is assumed to be 1.7 times that of the solution-phase cross section, the calculated effective quantum yield becomes 0.28 , leading to a threshold wavelength $\left(\lambda_{0}\right)$ of $336 \mathrm{~nm}$. Using this set of cross section and quantum yields, we calculated that the nitrate photolysis frequency was $3.1 \times 10^{-4} \mathrm{~s}^{-1}$ for SZA of $45^{\circ}$, and $4.6 \times 10^{-4} \mathrm{~s}^{-1}$ for SZA of $0^{\circ}$, which are 19 and $24 \%$ larger than results obtained using the condensed-phase cross section. The calculated ambient photolysis frequency is not affected as significantly by the change in the absorption cross section, because it is constrained by the measured photolysis frequency in the reaction chamber. When a larger cross section is applied, a smaller quantum yield is derived, and the calculated ambient photolysis frequency, being the integrated product of the 

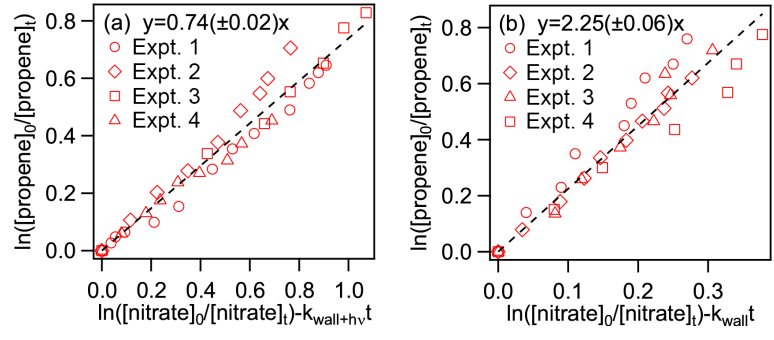

Figure 8. The first-order loss of propene relative to that of the nitrooxy enal for $\mathrm{OH}$-initiated (a) and $\mathrm{O}_{3}$-initiated (b) oxidation reactions.

cross section, quantum yield, and radiation, will not increase as much as the cross section. In addition to the cross section, our treatment of the wavelength-dependent quantum yield can also introduce uncertainty to the calculated results. If a constant effective quantum yield is used in the calculation, the ambient photolysis frequency is $2.0 \times 10^{-4} \mathrm{~s}^{-1}$ for SZA of $45^{\circ}$ and $2.8 \times 10^{-4} \mathrm{~s}^{-1}$ for SZA of $0^{\circ}$, which are 23 and $24 \%$ lower than assuming a threshold wavelength. Therefore, our calculated ambient photolysis frequency, based on condensed-phase absorption cross section and a threshold energy for unity quantum yield, has an uncertainty of $25 \%$. Since we believe that the cross sections are indeed larger in the gas phase, our best estimate is $3.1( \pm 0.8) \times 10^{-4} \mathrm{~s}^{-1}$ for $\mathrm{SZA}=45^{\circ}$.

Figure 8 shows the results for the relative rate experiments for the $\mathrm{OH}$-initiated and $\mathrm{O}_{3}$-initiated oxidation of the nitrooxy enal, with propene as the reference compound. The loss of the nitrooxy enal to wall uptake and photolysis is corrected when comparing the oxidative loss of the nitrate to that of propene, using the same method as Hallquist et al. (1997). The $\mathrm{OH}$ and $\mathrm{O}_{3}$ oxidation rate constants for propene are $3.0( \pm 0.5) \times 10^{-11} \mathrm{~cm}^{3}$ molecules $^{-1} \mathrm{~s}^{-1}$ (Klein et al., 1984; Zellner and Lorenz, 1984) and $1.00( \pm 0.06) \times 10^{-17} \mathrm{~cm}^{3}$ molecules ${ }^{-1} \mathrm{~s}^{-1} \quad$ (Herron and Huie, 1974; Treacy et al., 1992). These are the IUPAC preferred rate constants for $T=298 \mathrm{~K}$ (http://iupac.pole-ether.fr/). Hence, the $\mathrm{OH}$ and $\mathrm{O}_{3}$ oxidation rate constants for the isoprene nitrooxy enal are, based on the results from the relative rate experiments, $4.1( \pm 0.7) \times 10^{-11}$ and $4.4( \pm 0.3) \times 10^{-18} \mathrm{~cm}^{3}$ molecules ${ }^{-1} \mathrm{~s}^{-1}$, respectively, at $295 \mathrm{~K}$.

The $\mathrm{OH}$ oxidation rate constant for the nitrooxy enal can be estimated through the structure-activity relationship (SAR) approach proposed by Kwok and Atkinson (1995). The rate constant for $\mathrm{OH}$ addition to the double bond can be calculated as $k(-\mathrm{CH}=\mathrm{CH})$, which is $8.69 \times 10^{-11} \mathrm{~cm}^{3}$ molecules ${ }^{-1} \mathrm{~s}^{-1}$, multiplied by the two correction factors $\mathrm{C}(-\mathrm{CHO})$ and $\mathrm{C}\left(-\mathrm{CH}_{2} \mathrm{ONO}_{2}\right)$, which are 0.34 and 0.47 , respectively. The resulting $\mathrm{OH}$ addition rate constant is $1.39 \times 10^{-11} \mathrm{~cm}^{3}$ molecules ${ }^{-1} \mathrm{~s}^{-1}$. The rate constant for $\mathrm{H}$ abstraction from the $-\mathrm{CHO}$ group is
$1.61 \times 10^{-11} \mathrm{~cm}^{3}$ molecules ${ }^{-1} \mathrm{~s}^{-1}$, after multiplying by a correction factor of 1 for having a double bond at its $\alpha$ position. The rate constant for $\mathrm{H}$ abstraction from the methylene group is $3.7 \times 10^{-14} \mathrm{~cm}^{3}$ molecules ${ }^{-1} \mathrm{~s}^{-1}$, calculated by multiplying the base rate constant for methylene groups, which is $9.34 \times 10^{-13} \mathrm{~cm}^{3}$ molecules ${ }^{-1} \mathrm{~s}^{-1}$, by the correction factors of the nitrate group and the double bond, which are 0.04 and 1, respectively. $\mathrm{OH}$ addition to the nitrate group has a rate constant of $4.4 \times 10^{-13} \mathrm{~cm}^{3}$ molecule ${ }^{-1} \mathrm{~s}^{-1}$, after taking account of the enhancement factor of 1.23 for the methylene group. $\mathrm{H}$ abstraction from the methyl group has a rate constant of $1.36 \times 10^{-13} \mathrm{~cm}^{3}$ molecules ${ }^{-1} \mathrm{~s}^{-1}$. By summing up the rate constants for all these reaction pathways, the SAR-derived $\mathrm{OH}$ oxidation rate constant for the isoprene nitrooxy enal is $3.1 \times 10^{-11} \mathrm{~cm}^{3}$ molecules ${ }^{-1} \mathrm{~s}^{-1}$, approximately $30 \%$ lower than the experimental measurement. The dominant reaction channels are $\mathrm{OH}$ addition to the double bond and $\mathrm{H}$ abstraction from the aldehyde group. Contributions from the other reaction pathways are small $(<3 \%)$.

The relative importance of the three photochemical sinks, photolysis, $\mathrm{OH}$ oxidation, and $\mathrm{O}_{3}$ oxidation, depends on the solar radiation and the concentrations of $\mathrm{OH}$ and $\mathrm{O}_{3}$. To better illustrate their relative contributions, observations of $\mathrm{OH}$ and $\mathrm{O}_{3}$ from previous field campaigns were used to calculate the loss rates of the nitrooxy enal. The local solar radiation was calculated with the TUV model (Madronich and Flocke, 1998), which was then used to derive the photolysis frequency. The calculated results (Fig. 9) suggest that photolysis is a significant degradation pathway for the nitrooxy enal, which can dominate over $\mathrm{OH}$ oxidation toward midday. When the solar radiation intensity is small (such as 06:00 for the 1999 SOS campaign), OH oxidation is likely the dominant sink. Due to the fast photolysis and high reactivity toward $\mathrm{OH}$, the photochemical lifetime of the nitrooxy enal can be as short as less than $1 \mathrm{~h}$.

\subsection{Degradation products of the 4,1-isoprene nitrooxy enal}

\subsubsection{OH oxidation}

The products from the $\mathrm{OH}$-initiated oxidation of the isoprene nitrooxy enal were observed by the CIMS. The change in the CIMS signals before and after the reaction are illustrated in Fig. 10, along with assignment of some of the molecular structures based on the molecular weight and likely chemistry. The $\mathrm{OH}$-initiated oxidation reaction can proceed through two channels: $\mathrm{H}$ abstraction from the aldehyde group and $\mathrm{OH}$ addition to the double bond.

For the $\mathrm{H}$ abstraction pathway, a peroxyacyl nitrate (PAN) product was observed at $m / z 349$ (Fig. 10), which can be formed as shown in Fig. 11. The first-order dissociation rate constant for the PAN compound was determined at room temperature $(295 \mathrm{~K})$ using the following method. A $100 \mathrm{~L}$ Teflon bag containing the air mixture of approximately $1 \mathrm{ppm}$ 


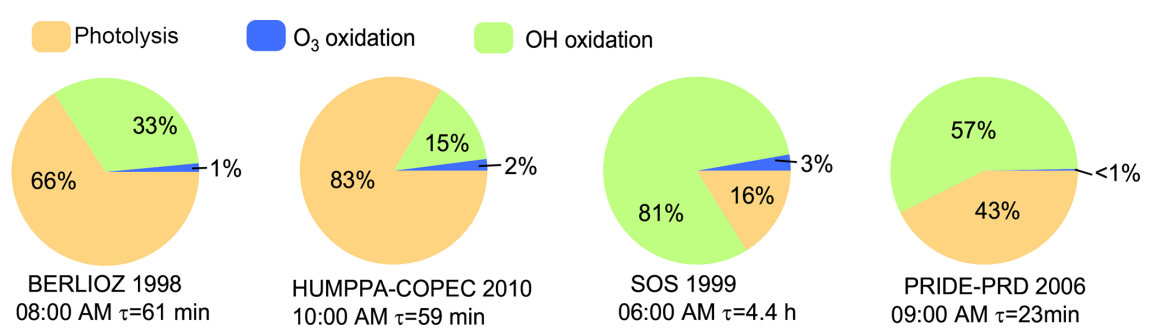

Figure 9. The relative contributions of photolysis (orange), $\mathrm{OH}$ oxidation (green), and $\mathrm{O}_{3}$ oxidation (blue) to the photochemical decay of the nitrooxy enal, calculated based on measured $\mathrm{OH}$ and $\mathrm{O}_{3}$ concentrations for the following field studies: BERLIOZ 1998 study in Pabstthum, Germany (Mihelcic et al., 2003; Platt et al., 2002); HUMPPA-COPEC 2010 study in Hyytiälä (Hens et al., 2014), Finland; SOS 1999 study in Nashville, USA (Martinez et al., 2003; Roberts et al., 2002); and PRIDE-PRD 2006 study in Guangzhou, China (Lu et al., 2012).

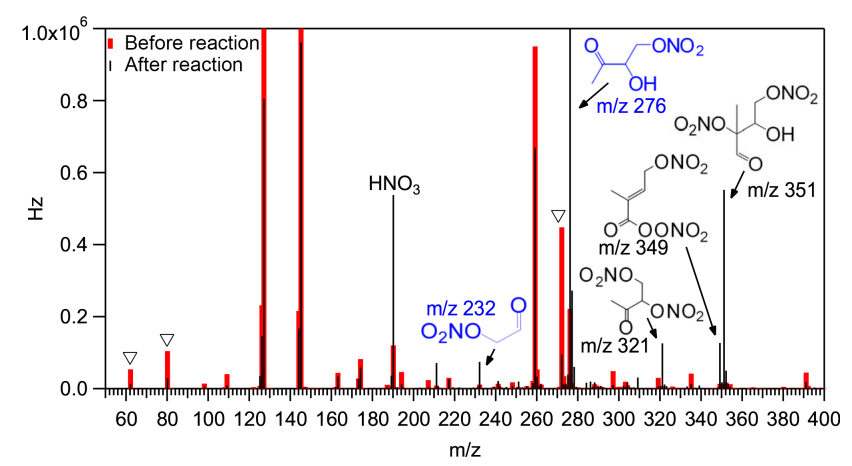

Figure 10. The CIMS spectra before (red) and after (black) the $\mathrm{OH}+$ nitrooxy enal oxidation reaction. The inverted triangles show the decreases in CIMS signals for the nitrooxy enal $(\mathrm{m} / z 272)$ and the $\mathrm{NO}_{3}^{-}$fragments $(m / z, 62$, water cluster at $m / z$ 80) derived from the carbonyl nitrate (Fig. 13). The molecular structures are inferred from the nominal masses observed by CIMS. The compounds that were observed by both CIMS and GC (Fig. 13) are colored in blue.

isopropyl nitrite and $30 \mathrm{ppb}$ isoprene nitrooxy enal was irradiated, and the PAN compound was formed when the nitrooxy enal reacted with $\mathrm{OH}$ and $\mathrm{NO}_{2}$ (produced through the photolysis of isopropyl nitrite). After 5 min reaction time, the bag was removed from the UV radiation, and NO was injected into the bag to around $4 \mathrm{ppm}$ in concentration. The bag was then sampled simultaneously by the CIMS, which monitored the decrease in the signal of the PAN compound, and by the TRENI, which monitored the concentrations of NO and $\mathrm{NO}_{2}$. The PAN dissociation reaction is a reversible process, where the dissociation products, peroxyacyl (PA) radical and $\mathrm{NO}_{2}$, can recombine to form PAN. With the addition of the large amount of NO, PA radicals are predominantly consumed by the irreversible $\mathrm{PA}+\mathrm{NO}$ reaction, leading to the decay of the PAN compound. The apparent PAN dissociation rate constant can be described by Eq. (6) (Shepson et al., 1992), where $k$ is the first-order loss rate constant measured by the CIMS (Fig. S6), $k_{\text {PAN }}$ is the real PAN dissociation rate constant, $[\mathrm{NO}]$ and $\left[\mathrm{NO}_{2}\right]$ are the concentrations for $\mathrm{NO}$ and $\mathrm{NO}_{2}$, and $k_{\mathrm{NO}}$ and $k_{\mathrm{NO}_{2}}$ are the rate constants for $\mathrm{PA}+\mathrm{NO}$ and $\mathrm{PA}+\mathrm{NO}_{2}$ reactions. Since the rate constants $k_{\mathrm{NO}}$ and $k_{\mathrm{NO}_{2}}$ for the nitrooxy enal-derived PA radical are unknown, the IUPAC recommended rate constants for the peroxyacetyl radicals $\left(\mathrm{CH}_{3} \mathrm{C}(\mathrm{O}) \mathrm{O}_{2}\right)$ are used, with $k_{\mathrm{NO}}=2.0 \times 10^{-11} \mathrm{~cm}^{3}$ molecule ${ }^{-1} \mathrm{~s}^{-1}$ and $k_{\mathrm{NO}_{2}}=$ $8.9 \times 10^{-12} \mathrm{~cm}^{3}$ molecule ${ }^{-1} \mathrm{~s}^{-1}$. The PAN dissociation rate constant, after correcting for the competing $\mathrm{PA}+\mathrm{NO}$ and $\mathrm{PA}+\mathrm{NO}_{2}$ reactions using Eq. (6), is $5.7( \pm 0.8) \times 10^{-4} \mathrm{~s}^{-1}$, based on three experimental trials. In addition to dissociation, the PAN compound in the $100 \mathrm{~L}$ bag could also undergo wall loss. This loss rate was estimated by multiplying the wall loss rate of the nitrooxy enal in the $5500 \mathrm{~L}$ chamber by a factor of 16 , which is the square diffusion distance of the chamber relative to that of the $100 \mathrm{~L} \mathrm{bag}$, assuming the PAN compound and the isoprene carbonyl nitrate have similar diffusion and adsorption coefficients. Considering the uncertainty in wall loss rate, the PAN dissociation rate constant is $5.7(+0.8 /-2.8) \times 10^{-4} \mathrm{~s}^{-1}$. Previous studies of the dissociation rate constants for peroxyacyl nitrates have reported results ranging from $1.6 \times 10^{-4} \mathrm{~s}^{-1}$ to $6.0 \times 10^{-4} \mathrm{~s}^{-1}$ at $298 \mathrm{~K}$ (Bridier et al., 1991; Grosjean et al., 1994; Kabir et al., 2014; Roberts and Bertman, 1992). Our result is consistent with previous work.

$k=k_{\mathrm{PAN}}\left(1-\frac{1}{1+\frac{k_{\mathrm{NO}}[\mathrm{NO}]}{k_{\mathrm{NO}_{2}}\left[\mathrm{NO}_{2}\right]}}\right)$

Since our $\mathrm{OH}$ oxidation experiments were conducted in the presence of high NO concentration, a significant fraction of the $\mathrm{PA}$ radicals from the $\mathrm{H}$ abstraction reaction channel were expected to react with $\mathrm{NO}$ to form alkoxy radicals. Based on the product observed at $m / z 321$, a reaction scheme (Fig. 11) is proposed, where the alkoxy radical dissociates into $\mathrm{CO}_{2}$ and an alkenyl radical, which is further oxidized to form a C4 dinitrate $(m / z 321$, Fig. 10), along with ethanal nitrate $(\mathrm{m} / \mathrm{z}$ 232, Fig. 10).

For the $\mathrm{OH}$ addition pathway, $\mathrm{OH}$ can add to the $\mathrm{C} 2$ and the $\mathrm{C} 3$ position of the isoprene nitrooxy enal, but the less substituted $\mathrm{C} 3$ position should be preferential (Peeters et al., 2007). For the $C 2$ addition, the expected nitrate products are C5 dinitrate and ethanal nitrate (Fig. 12a), and their nominal masses were observed at $m / z 351$ and $m / z 232$ (Fig. 10). 


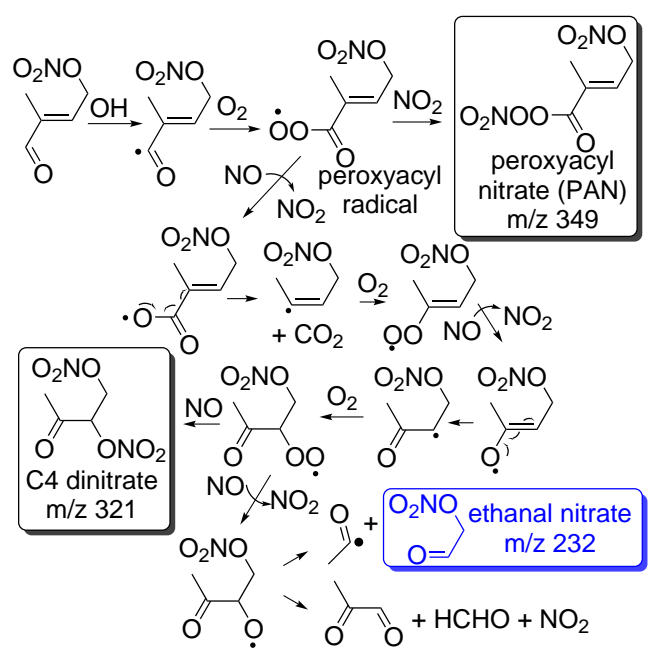

Figure 11. A proposed reaction mechanism for the $\mathrm{H}$ abstraction pathway for the $\mathrm{OH}+$ nitrooxy enal oxidation reaction. The compounds in boxes are products inferred from the nominal masses observed by the CIMS (Fig. 8). The compound colored in blue was observed by both GC and CIMS (Fig. 13).

$\mathrm{NO}_{2}$ could potentially be released with the concurrent formation of a C4 dialdehyde (Fig. 12a). The CIMS signal for this compound at $m / z 229$ did not increase (Fig. 10), but the CIMS sensitivity for this compound could be relatively low. For the $\mathrm{C} 3$ addition, the expected nitrate products are $\mathrm{C} 5$ dinitrate, methyl vinyl ketone (MVK) nitrate and ethanal nitrate (Fig. 12b), observed at $m / z 351, m / z 276$, and $m / z 232$ (Fig. 10). We assigned $m / z 276$ to solely MVK nitrate, instead of MACR nitrate, because the precursor nitrooxy enal has a secondary carbon at its $\mathrm{C} 3$ position, and the $\mathrm{OH}$ oxidation reaction cannot add a functional group at this position while still maintaining it as a secondary carbon as is the case for MACR nitrate. The $\mathrm{C} 2$ and $\mathrm{C} 3 \mathrm{OH}$ addition pathway would lead to two C5 dinitrate isomers, but they were detected at the same mass by the CIMS.

Using a gas chromatograph (GC) - electron capture detector (ECD)/CIMS method similar to the one described by Xiong et al. (2015), the CIMS sensitivities of the nitrate products were determined relative to the CIMS sensitivity of the isoprene nitrooxy enal. The setup was modified to operate the GC separation under pressure lower than 1 atm (Fig. S7), which helped to lower the elution temperature. A Teflon bag filled with the nitrooxy enal, isopropyl nitrite, and NO was irradiated to generate the $\mathrm{OH}$ oxidation products. The mixture of the nitrooxy enal and its products was then cryo-focused and separated on the GC column, and the eluent species were detected by the ECD and the CIMS simultaneously. We were able to quantify the MVK nitrate and the ethanal nitrate using this method, assuming identical ECD sensitivities for nitrates. The other products shown in Fig. 10, however, were not detected with simultaneous good signal-to-noise ratio on the ECD and the CIMS. The ECD/CIMS chromatograms are

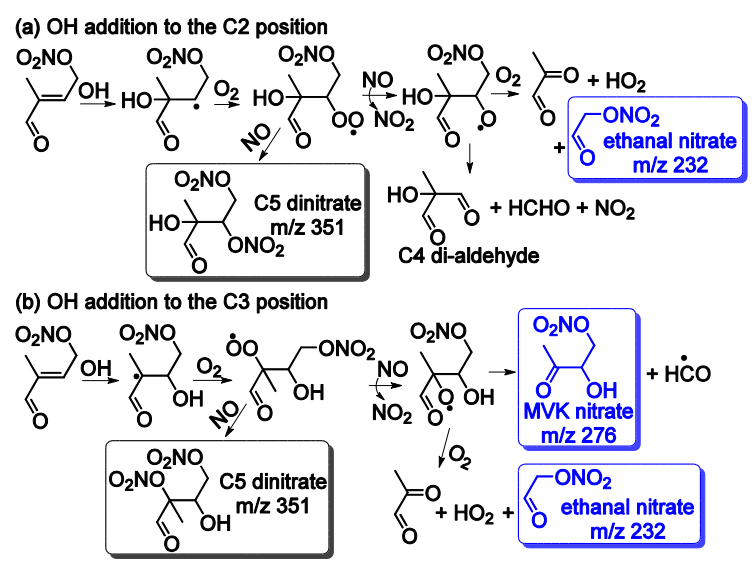

Figure 12. Proposed reaction mechanisms for $\mathrm{OH}$ addition to the C2 (a) and C3 (b) position of the nitrooxy enal. The compounds in boxes are products inferred from the nominal masses observed by the CIMS (Fig. 8). The compounds that were observed by both CIMS and GC (Fig. 13) are colored in blue.

shown in Fig. 13. We determined that the reaction of the isoprene nitrooxy enal with the reagent ion $\mathrm{I}^{-}$could form $\mathrm{NO}_{3}^{-}$, but the same reaction did not occur for the MVK nitrate and the ethanal nitrate (Fig. 13). Formation of $\mathrm{NO}_{3}^{-}$from $\mathrm{I}^{-}$reaction with organic nitrates has not been reported previously. Since $\mathrm{I}^{-}$is a poor nucleophile, it is unclear whether this reaction proceeds by $\mathrm{S}_{\mathrm{N}} 2$ substitution. Using the same $\mathrm{I}^{-}$ionization method, Wang et al. (2014) observed $\mathrm{NO}_{3}^{-}$signal equivalent to a $\mathrm{NO}_{3}+\mathrm{N}_{2} \mathrm{O}_{5}$ concentration of 200-1000 ppt during a field study in Hong Kong. Through interference tests, the authors attributed $30-50 \%$ of the observed $\mathrm{NO}_{3}^{-}$signal to the interference from peroxyacetyl nitrate and $\mathrm{NO}_{2}$. Since $\mathrm{I}^{-}$reaction with the nitrooxy enal can also generate $\mathrm{NO}_{3}^{-}$, organic nitrates $\left(\mathrm{RONO}_{2}\right)$ could be a potential source of interference for $\mathrm{NO}_{3}+\mathrm{N}_{2} \mathrm{O}_{5}$ measurement with the $\mathrm{I}^{-}$ionization method. For field measurement of isoprene nitrooxy enal, this compound could be mistakenly measured as $\mathrm{NO}_{3}^{-}$when iodide-based CIMS was used without tuning the instrument specifically to favor iodide-nitrate clustering. While no field observations of this type of compound have been reported to date, they can still potentially be an important $\mathrm{NO}_{y}$ reservoir. For instance, Brown et al. (2009) estimated that in the 2004 NEAQS study the total concentration of nitrates derived from $\mathrm{NO}_{3}+$ isoprene chemistry could reach 500 ppt. The carbonyl nitrates (nitrooxy enone and nitrooxy enal) can contribute to a significant fraction of the total.

For the GC-ECD/CIMS calibration, nine trials were conducted at three different pressures. The results are summarized in Table S2 in the Supplement. The relative CIMS sensitivities for the nitrooxy enal, ethanal nitrate, and MVK nitrate are $1: 15( \pm 3): 34( \pm 3)$, respectively. The absolute CIMS sensitivity of the isoprene nitrooxy enal was determined with standard gas samples prepared following Xiong et al. (2015), and the result was used to calculate the absolute 


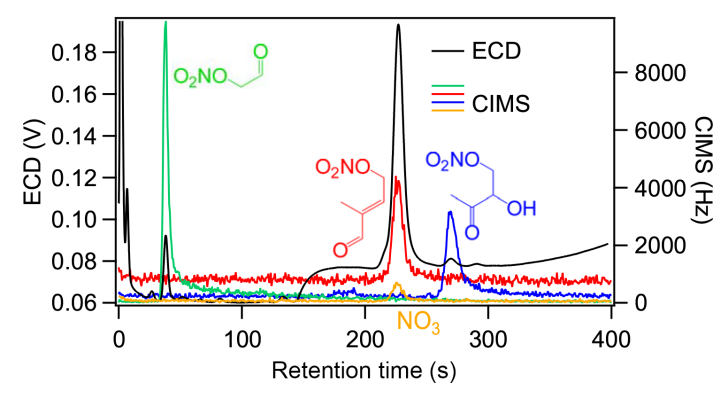

Figure 13. The GC-ECD/CIMS spectra for the nitrooxy enal (red), MVK nitrate (blue), and ethanal nitrate (green). The reaction of iodide with the nitrooxy enal generated $\mathrm{NO}_{3}^{-}$ion (orange). The ECD chromatogram is shown in black.

sensitivities for the ethanal nitrate and the MVK nitrate. The ethanal nitrate and the MVK nitrate both have the $-\mathrm{ONO}_{2}$ group at the $\beta$ position of the acidic $\mathrm{H}$, so their CIMS sensitivities are comparable. For the MVK nitrate, the electronwithdrawing ketone group can further enhance its gas-phase acidity and its affinity to bind with $\mathrm{I}^{-}$. Hence, the CIMS sensitivity for the MVK nitrate is greater than for the ethanal nitrate. For the nitrooxy enal, its low CIMS sensitivity can be caused by the trans $-\delta$ configuration of the $-\mathrm{ONO}_{2}$ group and the $-\mathrm{CHO}$ group. Our previous studies on isoprene-derived hydroxynitrates suggested that the CIMS sensitivity for the $\beta$ isomer is 8 times greater than for the trans- $\delta$ isomer (Xiong et al., 2015). Lee et al. (2014a) also reported the $\beta$ isomer sensitivity being over 16 times greater than the trans- $\delta$ isomer sensitivity, using iodide as the reagent ion. Hence, our calibration results, with the sensitivity for the ethanal nitrate 15 times greater than the sensitivity for the nitrooxy enal, is consistent with previous work.

With the CIMS sensitivities determined, the yield of the MVK nitrate and the ethanal nitrate from the $\mathrm{OH}$ initiated oxidation of the isoprene nitrooxy enal was obtained by comparing the formation of the products relative to the loss of the reactant (Fig. 14). The yield of the ethanal nitrate was corrected for loss to $\mathrm{OH}$ oxidation and photolysis, using the method described by Tuazon et al. (1984). The applied ethanal nitrate $+\mathrm{OH}$ rate constant was $3.4 \times 10^{-12} \mathrm{~cm}^{3}$ molecules ${ }^{-1} \mathrm{~s}^{-1}$, calculated using SAR. The applied photolysis frequency for ethanal nitrate was $1.69 \times 10^{-5} \mathrm{~s}^{-1}$, calculated with the cross section recommended by Müller et al. (2014) and a unity quantum yield. The yield of the MVK nitrate was corrected for loss to photolysis, wall uptake and $\mathrm{OH}$ oxidation using the same method as that for the ethanal nitrate yield. The applied photolysis frequency for the MVK nitrate was $4.5 \times 10^{-6} \mathrm{~s}^{-1}$, calculated using the absorption cross section of 3-nitrooxy-2butanone (Barnes et al., 1993) as a surrogate and unity quantum yield across all wavelengths (Müller et al., 2014). The MVK nitrate wall loss rate was set the same as that for the nitrooxy enal, because MVK nitrate has a molecular weight
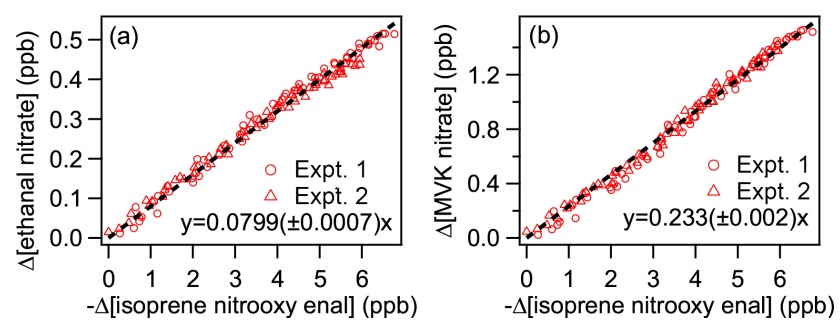

Figure 14. The formation of ethanal nitrate (a) and MVK nitrate (b) relative to the loss of the isoprene nitrooxy enal for the $\mathrm{OH}+$ nitrooxy enal oxidation experiments.

close to that of the nitrooxy enal. Based on the SAR method, we calculated that the rate constant for MVK nitrate reaction with $\mathrm{OH}$ should be $1.78 \times 10^{-12} \mathrm{~cm}^{3}$ molecules $^{-1} \mathrm{~s}^{-1}$. After the correction for secondary loss, the apparent yield is $23.3 \%$ for MVK nitrate and $8.0 \%$ for ethanal nitrate. Considering the uncertainties in the sensitivities of MVK nitrate and ethanal nitrate (Table S2), the MVK nitrate yield is $23( \pm 3) \%$, and the ethanal nitrate yield is $8( \pm 2) \%$. The fractional inlet sampling loss for the three nitrates was determined by comparing the CIMS signals of sampling through the $5.2 \mathrm{~m}$ long $50^{\circ} \mathrm{C}$ tubing and through a $20 \mathrm{~cm}$ room temperature tubing. By correcting for the inlet sampling loss, the MVK nitrate yield is $23( \pm 5) \%$, and the ethanal nitrate yield is $8( \pm 3) \%$. For the two $\mathrm{OH}$ oxidation experiments, the first-order loss rate of the nitrooxy enal was $3 \times 10^{-4} \mathrm{~s}^{-1}$ (Fig. S8). Since the total wall uptake and photolysis loss rate for nitrooxy enal was $4.3 \times 10^{-5} \mathrm{~s}^{-1}$, approximately $85 \%$ of the nitrooxy enal was lost to $\mathrm{OH}$ oxidation. After correcting for this factor, the MVK nitrate yield is $27( \pm 5) \%$, and the ethanal nitrate yield is $9( \pm 3) \%$. While we were able to determine the yields of MVK nitrate and ethanal nitrate from the $\mathrm{OH}$ oxidation reaction, the exact branching ratios for reactions described in Figs. 11 and 12 cannot be derived. This is because ethanal nitrate can be produced in both $\mathrm{H}$ abstraction and $\mathrm{OH}$ addition pathways (including both the (a) and (b) pathways). For MVK nitrate, even though it is produced in pathway (b) only, it has ethanal nitrate as a byproduct, making it impossible for us to determine the branching ratio for pathway (b).

\subsubsection{Photolysis}

Previous work on acetaldehyde suggests that at $313 \mathrm{~nm}$ the dominant photolysis reaction is dissociation of the $\mathrm{C}-\mathrm{CHO}$ bond, forming a formyl radical (.CHO) (Blacet and Loeffler, 1942). At shorter wavelength $(265 \mathrm{~nm})$, the reaction can proceed by intramolecular rearrangement forming $\mathrm{CH}_{4}$ and $\mathrm{CO}$ (Blacet and Loeffler, 1942). For compounds with longer carbon chain length, such as propyl- and butyl-aldehydes, the photo-dissociation reaction can produce alkenes and smaller aldehydes at 238 and $187 \mathrm{~nm}$ (Blacet and Crane, 1954). Since the UV radiation that reaches the earth's surface is mostly 


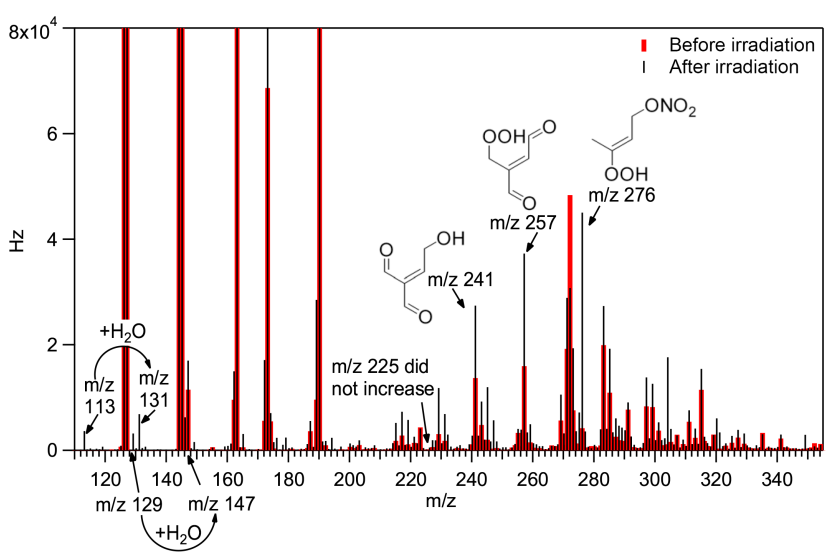

Figure 15. CIMS spectra before (red) and after (black) the photolysis of the isoprene nitrooxy enal. The molecular structures are inferred from the nominal masses observed by CIMS.

above $300 \mathrm{~nm}$, the formyl radical pathway is expected to be the most important photolysis reaction for alkyl aldehydes (Shepson and Heicklen, 1982). For the isoprene nitrooxy enal, the $\mathrm{C}-\mathrm{CHO}$ bond is strengthened by the delocalized electrons from the vinyl and the carbonyl groups, leading to a bond dissociation energy of $413 \mathrm{~kJ} \mathrm{~mol}^{-1}$, as measured for acrolein, which is larger than the $\mathrm{C}-\mathrm{CHO}$ bond dissociation energy of acetaldehyde $\left(355 \mathrm{~kJ} \mathrm{~mol}^{-1}\right)$ (Wiberg et al., 1992). In comparison, the $\mathrm{O}-\mathrm{NO}_{2}$ bond dissociation energy is $175 \mathrm{~kJ} \mathrm{~mol}^{-1}$ (Luo, 2007a), much lower than the dissociation energy of the $\mathrm{C}-\mathrm{CHO}$ bond. Hence, dissociation of the weak $\mathrm{O}-\mathrm{NO}_{2}$ bond may be an important reaction pathway for the nitrooxy enal. This process likely involves the absorption of a photon by the $\mathrm{C}=\mathrm{C}-\mathrm{C}=\mathrm{O}$ chromophore, followed by intramolecular energy redistribution to deposit energy into the $\mathrm{O}-\mathrm{NO}_{2}$ bond prior to dissociation. This reaction step would generate $\mathrm{NO}_{2}$ and an alkoxy radical, which upon reaction with $\mathrm{O}_{2}$ forms a conjugated dialdehyde.

Figure 15 shows the CIMS spectra before and after the photolysis of the isoprene nitrooxy enal. Cyclohexane was used as the $\mathrm{OH}$ scavenger for this experiment. The CIMS signal for the dialdehyde, which is the $\mathrm{O}-\mathrm{NO}_{2}$ bond dissociation product (reaction mechanism shown in Fig. 16), did not increase significantly. This may be because the CIMS was not sensitive to the dialdehyde, and/or the dialdehyde underwent rapid secondary reactions, rendering its steadystate concentration below the CIMS detection limit. Alternatively, it is possible that the alkoxy radical derived from $\mathrm{O}-\mathrm{NO}_{2}$ bond dissociation undergoes a $1,5-\mathrm{H}$ shift reaction (Fig. 16), rendering the formation of the dialdehyde an insignificant pathway. The resulting alkyl radical can immediately form a peroxy radical, which may follow the $\mathrm{H}$ shift mechanism proposed by Peeters et al. (2009) and form a hydroperoxy aldehyde (HPALD) compound, as observed at $m / z 257$ by the CIMS (Fig. 15). When the peroxy radical reacts with $\mathrm{NO}$ or $\mathrm{RO}_{2}$, the resulting alkoxy radical will

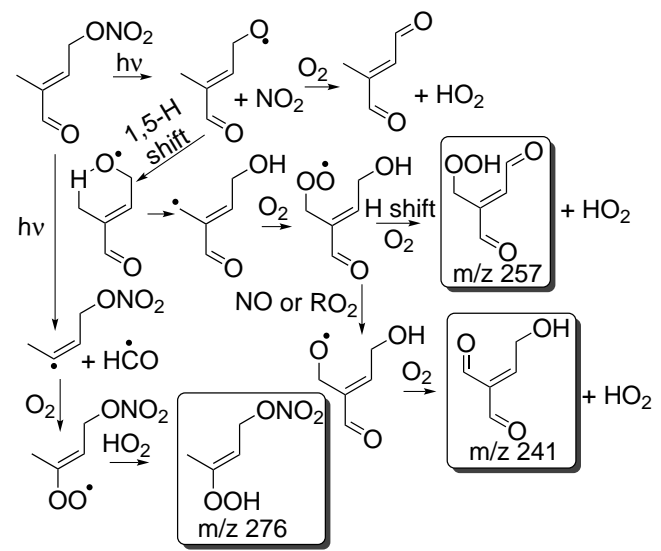

Figure 16. A proposed reaction mechanisms for the nitrooxy enal photolysis reaction. The compounds in boxes are products inferred from nominal masses observed by the CIMS (Fig. 15).

form a hydroxy dialdehyde (Fig. 16) with $m / z$ ratio at 241, which was also observed by the CIMS (Fig. 14). It is worth noting that we also observed CIMS signals for the deprotonated ions derived from the HPALD compound $(\mathrm{m} / z 129$ and $m / z$ 147) and the hydroxy dialdehyde $(m / z 113$ and $m / z$ 131). The proton transfer reaction between the iodide ion and alcohols/peroxides has not been observed previously, but it is possible that the conjugated structures help stabilize the charge and hence make the proton transfer reaction a viable reaction channel.

The product at $m / z 276$ has the molecular weight of MVK nitrate. In the presence of $\mathrm{OH}$ scavenger, however, the reaction is unlikely to proceed by the $\mathrm{OH}$-initiated oxidation pathway to form MVK nitrate. Instead, we hypothesize that the isoprene nitrooxy enal could dissociate via the $\mathrm{C}-\mathrm{CHO}$ bond, which, following reaction with $\mathrm{O}_{2}$ and $\mathrm{HO}_{2}$, would form a vinyl hydroperoxide with the same molecular weight as MVK nitrate. Vinyl hydroperoxides are known to be a reactive intermediate from the intramolecular $\mathrm{H}$ shift of Criegee biradical, which can decompose into $\mathrm{OH}$ and alkoxy radicals (Kroll et al., 2002). However, the un-energized vinyl hydroperoxides should have a lifetime long enough to be detected by mass spectrometers (Liu et al., 2015). In fact, theoretical calculations suggest that at $25^{\circ} \mathrm{C}$ vinyl hydroperoxide has a lifetime of $58 \mathrm{~h}$ (Richardson, 1995). Therefore, the product at $m / z 276$ is likely the vinyl hydroperoxide. For the $\mathrm{OH}$ oxidation product experiments, however, we attributed $m / z 276$ to MVK nitrate only, because $\mathrm{RO}_{2}+\mathrm{NO}$ reaction (forming MVK nitrate) should dominate over $\mathrm{RO}_{2}+\mathrm{HO}_{2}$ reaction (forming vinyl hydroperoxide), in the presence of high NO concentration.

Based on the CIMS spectra of the photolysis products, we conclude that the photolysis of the isoprene nitrooxy enal leads to the dissociation of both the $\mathrm{O}-\mathrm{NO}_{2}$ and the $\mathrm{C}-\mathrm{CHO}$ bonds. A reaction scheme is proposed in Fig. 16. While we were able to identify some of the photolysis products based 
on the nominal masses observed with the CIMS, the branching ratio for the two reaction pathways was not determined due to lack of quantitative measurements during the photolysis experiment. Future studies are needed to evaluate the relative importance of these two processes.

\section{Conclusions and future work}

An isoprene-derived nitrooxy enal model compound was synthesized to study its photochemical degradation chemistry in the atmosphere. The UV absorption spectrum of this compound has contributions from both the $\mathrm{C}=\mathrm{C}-\mathrm{C}=\mathrm{O}$ and the $-\mathrm{ONO}_{2}$ chromophores, as is confirmed by theoretical calculations, but absorption in the actinic region involves a transition involving the enal group. The combination of the $\mathrm{C}=\mathrm{C}-\mathrm{C}=\mathrm{O}$ and the $-\mathrm{ONO}_{2}$ chromophores enhances the $\mathrm{UV}$ cross section of this molecule relative to alkyl nitrates, making photolysis its dominant daytime sink. The photochemical lifetime of the nitrooxy enal can be less than $1 \mathrm{~h}$ due to its rapid photolysis loss, together with high reactivity toward $\mathrm{OH}$ and $\mathrm{O}_{3}$. The $\mathrm{OH}$ and $\mathrm{O}_{3}$ oxidation rate constants for the isoprene nitrooxy enal obtained in this study were both smaller than the reported rate constants for the $\delta$-isoprene hydroxy nitrates (Jacobs et al., 2014; Lee et al., $2014 b$ ). This could be because the oxidation by either $\mathrm{OH}$ or $\mathrm{O}_{3}$ would break the resonance structure of the $\mathrm{C}=\mathrm{C}-\mathrm{C}=\mathrm{O}$ moiety, thus increasing the activation energy.

Using the iodide-based CIMS, we identified the firstgeneration nitrate products from the $\mathrm{OH}$-initiated oxidation of the synthesized nitrooxy enal, including mononitrate, dinitrate, and nitrooxy peroxyacyl nitrate. Two of the products, the MVK nitrate and the ethanal nitrate, were quantified, which together contributed to $36( \pm 5) \%$ of the total products. The CIMS spectra of the nitrate photolysis products suggest that both the $\mathrm{C}-\mathrm{CHO}$ bond and the $\mathrm{O}-\mathrm{NO}_{2}$ bond dissociate in the reaction. Since photolysis is a significant sink for the nitrooxy enal, it is important for future studies to investigate the relative importance of the two reaction pathways, in order to fully understand the fate of $\mathrm{NO}_{x}$ in isoprene-rich atmospheres. Dissociation of the $\mathrm{O}-\mathrm{NO}_{2}$ bond may afford highly oxidized alcohol and hydroperoxide, which can potentially undergo uptake into the particle phase and facilitate the formation of secondary organic aerosols. The $\mathrm{C}-\mathrm{CHO}$ dissociation pathway may form a vinyl hydroperoxide product.

The $\mathrm{NO}_{3}$-initiated isoprene oxidation can produce a series of isomeric carbonyl nitrates. The 1,4-nitrooxy enal, which is the dominant isomer, is expected to have similar photolysis reactivity as the 4,1-nitrooxy enal studied in this work, because they both have the $\mathrm{O}=\mathrm{C}-\mathrm{C}=\mathrm{C}-\mathrm{C}$ chromophore and the $-\mathrm{ONO}_{2}$ chromophore, which would enhance the molecular absorption cross section. For the unsaturated ketones (enones) derived from isoprene oxidation, the ketone functionality may reduce their reactivity toward $\mathrm{OH}$, in com- parison with aldehydes, but we expect them to have similar photochemical properties as the nitrooxy enals, since isomers such as MVK and MACR have similar absorption cross sections and quantum yields (Gierczak et al., 1997).

The experiments in this work were conducted in the presence of relatively high NO concentration. In the ambient environment, organic nitrates produced in the high $\mathrm{NO}_{x}$ regime can undergo photochemical degradation in the low $\mathrm{NO}$ regime due to the wide span of ambient $\mathrm{NO}_{x}$ concentrations (Su et al., 2015; Xiong et al., 2015). Crounse et al. (2012) proposed that under low NO conditions, the oxidation of MACR can regenerate $\mathrm{OH}$ radicals and form a lactone that is prone to reactive uptake onto the aerosol phase. Since the isoprene nitrooxy enal has a structure similar to that of MACR, it might also undergo similar reaction in the clean environment. Further experimental work is needed to investigate how the photochemical oxidation process of the nitrooxy enal can influence the formation of $\mathrm{OH}$ radicals and growth of secondary organic aerosols.

\section{The Supplement related to this article is available online at doi:10.5194/acp-16-5595-2016-supplement.}

Acknowledgements. This research was supported in part through computational resources provided by Information Technology at Purdue University. We thank the National Science Foundation for supporting C. H. Borca and L. V. Slipchenko (grant CHE-1465154) and F. Xiong and P. B. Shepson (grant AGS-1228496).

Edited by: T. Bartels-Rausch

\section{References}

Aschmann, S. M., Tuazon, E. C., Arey, J., and Atkinson, R.: Products of the $\mathrm{OH}$ radical-initiated reactions of 2-propyl nitrate, 3-methyl-2-butyl nitrate and 3-methyl-2-pentyl nitrate, Atmos. Environ., 45, 1695-1701, doi:10.1016/j.atmosenv.2010.12.061, 2011.

Atkinson, R. and Aschmann, S. M.: Kinetics of the gas phase reaction of $\mathrm{Cl}$ atoms with a series of organics at $296 \pm 2 \mathrm{~K}$ and atmospheric pressure, Int. J. Chem. Kinet., 17, 33-41, doi:10.1002/kin.550170105, 1985.

Atkinson, R., Baulch, D. L., Cox, R. A., Crowley, J. N., Hampson, R. F., Hynes, R. G., Jenkin, M. E., Rossi, M. J., and Troe, J.: Evaluated kinetic and photochemical data for atmospheric chemistry: Volume III - gas phase reactions of inorganic halogens, Atmos. Chem. Phys., 7, 981-1191, doi:10.5194/acp-7-981-2007, 2007.

Barnes, I., Becker, K. H., and Zhu, T.: Near UV absorption spectra and photolysis products of difunctional organic nitrates: Possible importance as $\mathrm{NO}_{x}$ reservoirs, J. Atmos. Chem., 17, 353-373, doi:10.1007/bf00696854, 1993.

Bayliss, N. S. and McRae, E. G.: Solvent Effects in the Spectra of Acetone, Crotonaldehyde, Nitromethane and Nitrobenzene, J. Phys. Chem., 58, 1006-1011, 10.1021/j150521a018, 1954. 
Blacet, F. E.: Photochemistry in the Lower Atmosphere, Ind. Eng. Chem., 44, 1339-1342, doi:10.1021/ie50510a044, 1952.

Blacet, F. E. and Crane, R. A.: The Photolysis of the Aliphatic Aldehydes. XVII. Propionaldehyde, n-Butyraldehyde and Isobutyraldehyde at 2380 and $1870 \AA$ A., J. Am. Chem. Soc., 76, $5337-$ 5340, doi:10.1021/ja01650a020, 1954.

Blacet, F. E. and Loeffler, D. E.: The Photolysis of the Aliphatic Aldehydes. XI. Acetaldehyde and Iodine Mixtures, J. Am. Chem. Soc., 64, 893-896, doi:10.1021/ja01256a045, 1942.

Braun, W., Fahr, A., Klein, R., Kurylo, M. J., and Huie, R. E.: UV gas and liquid phase absorption cross section measurements of hydrochlorofluorocarbons HCFC-225ca and HCFC-225cb, J. Geophys. Res.-Atmos., 96, 13009-13015, doi:10.1029/91JD01026, 1991.

Bridier, I., Caralp, F., Loirat, H., Lesclaux, R., Veyret, B., Becker, K. H., Reimer, A., and Zabel, F.: Kinetic and theoretical studies of the reactions acetylperoxy + nitrogen dioxide $+\mathrm{M}$ .dblarw. acetyl peroxynitrate $+\mathrm{M}$ between 248 and $393 \mathrm{~K}$ and between 30 and 760 torr, J. Phys. Chem., 95, 3594-3600, doi:10.1021/j100162a031, 1991.

Brown, S. S., deGouw, J. A., Warneke, C., Ryerson, T. B., Dubé, W. P., Atlas, E., Weber, R. J., Peltier, R. E., Neuman, J. A., Roberts, J. M., Swanson, A., Flocke, F., McKeen, S. A., Brioude, J., Sommariva, R., Trainer, M., Fehsenfeld, F. C., and Ravishankara, A. R.: Nocturnal isoprene oxidation over the Northeast United States in summer and its impact on reactive nitrogen partitioning and secondary organic aerosol, Atmos. Chem. Phys., 9, 30273042, doi:10.5194/acp-9-3027-2009, 2009.

Chai, J.-D. and Head-Gordon, M.: Long-range corrected hybrid density functionals with damped atom-atom dispersion corrections, Phys. Chem. Chem. Phys., 10, 6615-6620, doi:10.1039/B810189B, 2008.

Chameides, W. and Walker, J. C. G.: A photochemical theory of tropospheric ozone, J. Geophys. Res., 78, 8751-8760, doi:10.1029/JC078i036p08751, 1973.

Chameides, W., Lindsay, R., Richardson, J., and Kiang, C.: The role of biogenic hydrocarbons in urban photochemical smog: Atlanta as a case study, Science, 241, 1473-1475, doi:10.1126/science.3420404, 1988.

Chameides, W. L., Fehsenfeld, F., Rodgers, M. O., Cardelino, C., Martinez, J., Parrish, D., Lonneman, W., Lawson, D. R., Rasmussen, R. A., Zimmerman, P., Greenberg, J., Mlddleton, P., and Wang, T.: Ozone precursor relationships in the ambient atmosphere, J. Geophys. Res.-Atmos., 97, 6037-6055, doi:10.1029/91JD03014, 1992.

Chen, X., Hulbert, D., and Shepson, P. B.: Measurement of the organic nitrate yield from $\mathrm{OH}$ reaction with isoprene, J. Geophys. Res., 103, 25563, doi:10.1029/98jd01483, 1998.

Crounse, J. D., Knap, H. C., Ornso, K. B., Jorgensen, S., Paulot, F., Kjaergaard, H. G., and Wennberg, P. O.: Atmospheric fate of methacrolein. 1. Peroxy radical isomerization following addition of $\mathrm{OH}$ and $\mathrm{O}_{2}$, J. Phys. Chem. A, 116, 5756-5762, doi:10.1021/jp211560u, 2012.

Darer, A. I., Cole-Filipiak, N. C., O'Connor, A. E., and Elrod, M. J.: Formation and stability of atmospherically relevant isoprenederived organosulfates and organonitrates, Environ. Sci. Technol., 45, 1895-1902, doi:10.1021/es103797z, 2011.

Ferris, A. F., McLean, K. W., Marks, I. G., and Emmons, W. D.: Metathetical Reactions of Silver Salts in Solution. III. The Syn- thesis of Nitrate Esters1, J. Am. Chem. Soc., 75, 4078-4078, doi:10.1021/ja01112a505, 1953.

Frisch, M. J., Pople, J. A., and Binkley, J. S.: Self-consistent molecular orbital methods 25. Supplementary functions for Gaussian basis sets, J. Chem. Phys., 80, 3265-3269, doi:10.1063/1.447079, 1984.

Giacopelli, P., Ford, K., Espada, C., and Shepson, P. B.: Comparison of the measured and simulated isoprene nitrate distributions above a forest canopy, J. Geophys. Res., 110, D01304, doi:10.1029/2004jd005123, 2005.

Gierczak, T., Burkholder, J. B., Talukdar, R. K., Mellouki, A., Barone, S. B., and Ravishankara, A. R.: Atmospheric fate of methyl vinyl ketone and methacrolein, J. Photochem. Photobio. A, 110, 1-10, doi:10.1016/S1010-6030(97)00159-7, 1997.

Gilbert, A. T. B.: IQmol molecular viewer, available at: http://iqmol. org (last access:10 April 2015), 2012.

Gray, G. M.: Method for the preparation of (E)-4-bromo-2methylbut-2-en-1-al, US Patent NO. 4288635, available at: http://patft.uspto.gov/netacgi/nph-Parser?Sect1=PTO2\&Sect2= HITOFF \&p=1\&u=\%2Fnetahtml\%2FPTO\%2Fsearch-bool. $\mathrm{html} \& \mathrm{r}=1 \& \mathrm{f}=\mathrm{G} \& \mathrm{l}=50 \& \mathrm{co} 1=\mathrm{AND} \& \mathrm{~d}=\mathrm{PTXT} \& \mathrm{~s} 1=4288635$. PN.\&OS=PN/4288635\&RS=PN/4288635 (last access: 2 May 2015), 1981.

Grosjean, D., Grosjean, E., and Williams, E. L.: Thermal decomposition of C3-substituted peroxyacyl nitrates, Res. Chem. Intermed., 20, 447-461, doi:10.1163/156856794X00414, 1994.

Grossenbacher, J. W., Barket Jr., D. J., Shepson, P. B., Carroll, M. A., Olszyna, K., and Apel, E.: A comparison of isoprene nitrate concentrations at two forest-impacted sites, J. Geophys. Res.Atmos., 109, D11311, doi:10.1029/2003JD003966, 2004.

Haagen-Smit, A. J.: Chemistry and Physiology of Los Angeles Smog, Ind. Eng. Chem., 44, 1342-1346, doi:10.1021/ie50510a045, 1952.

Hallquist, M., Wängberg, I., and Ljungström, E.: Atmospheric Fate of Carbonyl Oxidation Products Originating from $\alpha$ Pinene and $\Delta 3$-Carene: Determination of Rate of Reaction with $\mathrm{OH}$ and $\mathrm{NO}_{3}$ Radicals, UV Absorption Cross Sections, and Vapor Pressures, Environ. Sci. Technol., 31, 3166-3172, doi:10.1021/es970151a, 1997.

Hens, K., Novelli, A., Martinez, M., Auld, J., Axinte, R., Bohn, B., Fischer, H., Keronen, P., Kubistin, D., Nölscher, A. C., Oswald, R., Paasonen, P., Petäjä, T., Regelin, E., Sander, R., Sinha, V., Sipilä, M., Taraborrelli, D., Tatum Ernest, C., Williams, J., Lelieveld, J., and Harder, H.: Observation and modelling of $\mathrm{HO}_{x}$ radicals in a boreal forest, Atmos. Chem. Phys., 14, 8723-8747, doi:10.5194/acp-14-8723-2014, 2014.

Herron, J. T. and Huie, R. E.: Rate constants for the reactions of ozone with ethene and propene, from 235.0 to 362.0.deg.K, J. Phys. Chem., 78, 2085-2088, doi:10.1021/j100614a004, 1974.

Hohenberg, P. and Kohn, W.: Inhomogeneous Electron Gas, Phys. Rev., 136, B864-B871, 1964.

Horowitz, L. W., Fiore, A. M., Milly, G. P., Cohen, R. C., Perring, A., Wooldridge, P. J., Hess, P. G., Emmons, L. K., and Lamarque, J.-F.: Observational constraints on the chemistry of isoprene nitrates over the eastern United States, J. Geophys. Res., 112, D12S08, doi:10.1029/2006jd007747, 2007.

Hu, K. S., Darer, A. I., and Elrod, M. J.: Thermodynamics and kinetics of the hydrolysis of atmospherically relevant organon- 
itrates and organosulfates, Atmos. Chem. Phys., 11, 8307-8320, doi:10.5194/acp-11-8307-2011, 2011.

Jacobs, M. I., Burke, W. J., and Elrod, M. J.: Kinetics of the reactions of isoprene-derived hydroxynitrates: gas phase epoxide formation and solution phase hydrolysis, Atmos. Chem. Phys., 14, 8933-8946, doi:10.5194/acp-14-8933-2014, 2014.

Kabir, M., Jagiella, S., and Zabel, F.: Thermal Stability of n-Acyl Peroxynitrates, Int. J. Chem. Kinet., 46, 462-469, doi:10.1002/kin.20862, 2014.

Klein, T., Barnes, I., Becker, K. H., Fink, E. H., and Zabel, F.: Pressure dependence of the rate constants for the reactions of ethene and propene with hydroxyl radicals at $295 \mathrm{~K}$, J. Phys. Chem., 88, 5020-5025, doi:10.1021/j150665a046, 1984.

Kohn, W. and Sham, L. J.: Self-Consistent Equations Including Exchange and Correlation Effects, Phys. Rev., 140, A1133-A1138, 1965.

Kroll, J. H., Donahue, N. M., Cee, V. J., Demerjian, K. L., and Anderson, J. G.: Gas-Phase Ozonolysis of Alkenes: Formation of OH from Anti Carbonyl Oxides, J. Am. Chem. Soc., 124, 85188519, doi:10.1021/ja0266060, 2002.

Kwan, A. J., Chan, A. W. H., Ng, N. L., Kjaergaard, H. G., Seinfeld, J. H., and Wennberg, P. O.: Peroxy radical chemistry and $\mathrm{OH}$ radical production during the $\mathrm{NO}_{3}$-initiated oxidation of isoprene, Atmos. Chem. Phys., 12, 7499-7515, doi:10.5194/acp-12-74992012, 2012.

Kwok, E. S. C. and Atkinson, R.: Estimation of hydroxyl radical reaction rate constants for gas-phase organic compounds using a structure-reactivity relationship: An update, Atmos. Environ., 29, 1685-1695, doi:10.1016/1352-2310(95)00069-B, 1995.

Lee, B. H., Lopez-Hilfiker, F. D., Mohr, C., Kurtén, T., Worsnop, D. R., and Thornton, J. A.: An Iodide-Adduct High-Resolution Time-of-Flight Chemical-Ionization Mass Spectrometer: Application to Atmospheric Inorganic and Organic Compounds, Environ. Sci. Technol., 48, 6309-6317, doi:10.1021/es500362a, 2014a.

Lee, L., Teng, A. P., Wennberg, P. O., Crounse, J. D., and Cohen, R. C.: On rates and mechanisms of $\mathrm{OH}$ and $\mathrm{O}_{3}$ reactions with isoprene-derived hydroxy nitrates, J. Phys. Chem. A, 118, 16221637, doi:10.1021/jp4107603, 2014b.

Lefohn, A. S. and Foley, J. K.: Establishing Relevant Ozone Standards to Protect Vegetation and Human Health: Exposure/Dose-Response Considerations, Air Waste, 43, 106-112, doi:10.1080/1073161X.1993.10467111, 1993.

Linder, B. and Abdulnur, S.: Solvent Effects on Electronic Spectral Intensities, J. Chem. Phys., 54, 1807-1814, doi:10.1063/1.1675088, 1971.

Lippmann, M.: HEALTH EFFECTS OF OZONE A Critical Review, JAPCA, 39, 672-695, doi:10.1080/08940630.1989.10466554, 1989.

Liu, F., Fang, Y., Kumar, M., Thompson, W. H., and Lester, M. I.: Direct observation of vinyl hydroperoxide, Phys. Chem. Chem. Phys., 17, 20490-20494, doi:10.1039/C5CP02917A, 2015.

Lockwood, A. L., Shepson, P. B., Fiddler, M. N., and Alaghmand, M.: Isoprene nitrates: preparation, separation, identification, yields, and atmospheric chemistry, Atmos. Chem. Phys., 10, 6169-6178, doi:10.5194/acp-10-6169-2010, 2010.

Lu, K. D., Rohrer, F., Holland, F., Fuchs, H., Bohn, B., Brauers, T., Chang, C. C., Häseler, R., Hu, M., Kita, K., Kondo, Y., Li, X., Lou, S. R., Nehr, S., Shao, M., Zeng, L. M., Wahner, A., Zhang,
Y. H., and Hofzumahaus, A.: Observation and modelling of $\mathrm{OH}$ and $\mathrm{HO}_{2}$ concentrations in the Pearl River Delta 2006: a missing $\mathrm{OH}$ source in a VOC rich atmosphere, Atmos. Chem. Phys., 12, 1541-1569, doi:10.5194/acp-12-1541-2012, 2012.

Luo, Y.-R.: BDEs of O-X bonds, in: Comprehensive Handbook of Chemical Bond Energies, 351, CRC Press, Boca Raton, FL, 2007a.

Luo, Y.-R.: BDEs in the halogenated molecules, clusters and complexes, in: Comprehensive Handbook of Chemical Bond Energies, 1351-1427, CRC Press, Boca Raton, FL, 2007 b.

Madronich, S. and Flocke, S.: The role of solar radiation in atmospheric chemistry, in: Handbook of Environmental Chemistry, edited by: Boule, P., Springer-Verlag, Heidelberg, 1-26, 1998.

Mao, J., Paulot, F., Jacob, D. J., Cohen, R. C., Crounse, J. D., Wennberg, P. O., Keller, C. A., Hudman, R. C., Barkley, M. P., and Horowitz, L. W.: Ozone and organic nitrates over the eastern United States: Sensitivity to isoprene chemistry, J. Geophys. Res.-Atmos., 118, 11256-11268, doi:10.1002/jgrd.50817, 2013.

Martinez, M., Harder, H., Kovacs, T. A., Simpas, J. B., Bassis, J., Lesher, R., Brune, W. H., Frost, G. J., Williams, E. J., Stroud, C. A., Jobson, B. T., Roberts, J. M., Hall, S. R., Shetter, R. E., Wert, B., Fried, A., Alicke, B., Stutz, J., Young, V. L., White, A. B., and Zamora, R. J.: $\mathrm{OH}$ and $\mathrm{HO}_{2}$ concentrations, sources, and loss rates during the Southern Oxidants Study in Nashville, Tennessee, summer 1999, J. Geophys. Res.-Atmos., 108, 4617, doi:10.1029/2003JD003551, 2003.

Mihelcic, D., Holland, F., Hofzumahaus, A., Hoppe, L., Konrad, S., Müsgen, P., Pätz, H. W., Schäfer, H. J., Schmitz, T., VolzThomas, A., Bächmann, K., Schlomski, S., Platt, U., Geyer, A., Alicke, B., and Moortgat, G. K.: Peroxy radicals during BERLIOZ at Pabsthum: Measurements, radical budgets and ozone production, J. Geophys. Res.-Atmos., 108, 8254, doi:10.1029/2001JD001014, 2003.

Müller, J.-F., Peeters, J., and Stavrakou, T.: Fast photolysis of carbonyl nitrates from isoprene, Atmos. Chem. Phys., 14, $2497-$ 2508, doi:10.5194/acp-14-2497-2014, 2014.

Neuman, J. A., Nowak, J. B., Huey, L. G., Burkholder, J. B., Dibb, J. E., Holloway, J. S., Liao, J., Peischl, J., Roberts, J. M., Ryerson, T. B., Scheuer, E., Stark, H., Stickel, R. E., Tanner, D. J., and Weinheimer, A.: Bromine measurements in ozone depleted air over the Arctic Ocean, Atmos. Chem. Phys., 10, 6503-6514, doi:10.5194/acp-10-6503-2010, 2010.

Noyes, W. A.: Explanation of the Formation of Alkyl Nitrites in Dilute Solutions; Butyl and Amyl Nitrites, J. Am. Chem. Soc., 55, 3888-3889, doi:10.1021/ja01336a503, 1933.

Parrish, D. D., Lamarque, J. F., Naik, V., Horowitz, L., Shindell, D. T., Staehelin, J., Derwent, R., Cooper, O. R., Tanimoto, H., Volz-Thomas, A., Gilge, S., Scheel, H. E., Steinbacher, M., and Fröhlich, M.: Long-term changes in lower tropospheric baseline ozone concentrations: Comparing chemistry-climate models and observations at northern midlatitudes, J. Geophys. Res.-Atmos., 119, 5719-5736, doi:10.1002/2013JD021435, 2014.

Patchen, A. K., Pennino, M. J., Kiep, A. C., and Elrod, M. J.: Direct kinetics study of the product-forming channels of the reaction of isoprene-derived hydroxyperoxy radicals with NO, Int. J. Chem. Kinet., 39, 353-361, doi:10.1002/kin.20248, 2007.

Paulot, F., Crounse, J. D., Kjaergaard, H. G., Kroll, J. H., Seinfeld, J. H., and Wennberg, P. O.: Isoprene photooxidation: new insights 
into the production of acids and organic nitrates, Atmos. Chem. Phys., 9, 1479-1501, doi:10.5194/acp-9-1479-2009, 2009.

Paulot, F., Henze, D. K., and Wennberg, P. O.: Impact of the isoprene photochemical cascade on tropical ozone, Atmos. Chem. Phys., 12, 1307-1325, doi:10.5194/acp-12-1307-2012, 2012.

Peeters, J., Boullart, W., Pultau, V., Vandenberk, S., and Vereecken, L.: Structure-Activity Relationship for the Addition of $\mathrm{OH}$ to (Poly)alkenes: Site-Specific and Total Rate Constants, J. Phys. Chem. A, 111, 1618-1631, doi:10.1021/jp066973o, 2007.

Peeters, J., Nguyen, T. L., and Vereecken, L.: $\mathrm{HO}_{x}$ radical regeneration in the oxidation of isoprene, Phys. Chem. Chem. Phys., 11, 5935-5939, doi:10.1039/b908511d, 2009.

Perring, A. E., Wisthaler, A., Graus, M., Wooldridge, P. J., Lockwood, A. L., Mielke, L. H., Shepson, P. B., Hansel, A., and Cohen, R. C.: A product study of the isoprene $+\mathrm{NO}_{3}$ reaction, Atmos. Chem. Phys., 9, 4945-4956, doi:10.5194/acp-9-4945-2009, 2009.

Platt, U., Alicke, B., Dubois, R., Geyer, A., Hofzumahaus, A., Holland, F., Martinez, M., Mihelcic, D., Klüpfel, T., Lohrmann, B., Pätz, W., Perner, D., Rohrer, F., Schäfer, J., and Stutz, J.: Free Radicals and Fast Photochemistry during BERLIOZ, J. Atmos. Chem., 42, 359-394, doi:10.1023/A:1015707531660, 2002.

Richardson, W. H.: An Evaluation of Vinyl Hydroperoxide as an Isolable Molecule, J. Org. Chem., 60, 4090-4095, doi:10.1021/jo00118a027, 1995.

Rindelaub, J. D., McAvey, K. M., and Shepson, P. B.: The photochemical production of organic nitrates from $\alpha$-pinene and loss via acid-dependent particle phase hydrolysis, Atmos. Environ., 100, 193-201, doi:10.1016/j.atmosenv.2014.11.010, 2015.

Roberts, J. M.: The atmospheric chemistry of organic nitrates, Atmos. Environ. A-Gen., 24, 243-287, doi:10.1016/09601686(90)90108-Y, 1990.

Roberts, J. M. and Bertman, S. B.: The thermal decomposition of peroxyacetic nitric anhydride (PAN) and peroxymethacrylic nitric anhydride (MPAN), Int. J. Chem. Kinet., 24, 297-307, doi:10.1002/kin.550240307, 1992.

Roberts, J. M., Flocke, F., Stroud, C. A., Hereid, D., Williams, E., Fehsenfeld, F., Brune, W., Martinez, M., and Harder, H.: Ground-based measurements of peroxycarboxylic nitric anhydrides (PANs) during the 1999 Southern Oxidants Study Nashville Intensive, J. Geophys. Res.-Atmos., 107, ACH 1-1ACH 1-10, doi:10.1029/2001JD000947, 2002.

Rollins, A. W., Kiendler-Scharr, A., Fry, J. L., Brauers, T., Brown, S. S., Dorn, H.-P., Dubé, W. P., Fuchs, H., Mensah, A., Mentel, T. F., Rohrer, F., Tillmann, R., Wegener, R., Wooldridge, P. J., and Cohen, R. C.: Isoprene oxidation by nitrate radical: alkyl nitrate and secondary organic aerosol yields, Atmos. Chem. Phys., 9, 6685-6703, doi:10.5194/acp-9-6685-2009, 2009.

Runge, E. and Gross, E. K. U.: Density-Functional Theory for Time-Dependent Systems, Phys. Rev. Lett., 52, 997-1000, 1984.

Schwantes, R. H., Teng, A. P., Nguyen, T. B., Coggon, M. M., Crounse, J. D., St. Clair, J. M., Zhang, X., Schilling, K. A., Seinfeld, J. H., and Wennberg, P. O.: Isoprene $\mathrm{NO}_{3}$ Oxidation Products from the $\mathrm{RO}_{2}+\mathrm{HO}_{2}$ Pathway, J. Phys. Chem. A, 119, 10158-10171, doi:10.1021/acs.jpca.5b06355, 2015.

Shao, Y., Gan, Z., Epifanovsky, E., Gilbert, A. T. B., Wormit, M., Kussmann, J., Lange, A. W., Behn, A., Deng, J., Feng, X., Ghosh, D., Goldey, M., Horn, P. R., Jacobson, L. D., Kaliman, I., Khaliullin, R. Z., Kuś, T., Landau, A., Liu, J., Proynov, E. I., Rhee,
Y. M., Richard, R. M., Rohrdanz, M. A., Steele, R. P., Sundstrom, E. J., Woodcock, H. L., Zimmerman, P. M., Zuev, D., Albrecht, B., Alguire, E., Austin, B., Beran, G. J. O., Bernard, Y. A., Berquist, E., Brandhorst, K., Bravaya, K. B., Brown, S. T., Casanova, D., Chang, C.-M., Chen, Y., Chien, S. H., Closser, K. D., Crittenden, D. L., Diedenhofen, M., DiStasio, R. A., Do, H., Dutoi, A. D., Edgar, R. G., Fatehi, S., Fusti-Molnar, L., Ghysels, A., Golubeva-Zadorozhnaya, A., Gomes, J., Hanson-Heine, M. W. D., Harbach, P. H. P., Hauser, A. W., Hohenstein, E. G., Holden, Z. C., Jagau, T.-C., Ji, H., Kaduk, B., Khistyaev, K., Kim, J., Kim, J., King, R. A., Klunzinger, P., Kosenkov, D., Kowalczyk, T., Krauter, C. M., Lao, K. U., Laurent, A. D., Lawler, K. V., Levchenko, S. V., Lin, C. Y., Liu, F., Livshits, E., Lochan, R. C., Luenser, A., Manohar, P., Manzer, S. F., Mao, S.-P., Mardirossian, N., Marenich, A. V., Maurer, S. A., Mayhall, N. J., Neuscamman, E., Oana, C. M., Olivares-Amaya, R., O’Neill, D. P., Parkhill, J. A., Perrine, T. M., Peverati, R., Prociuk, A., Rehn, D. R., Rosta, E., Russ, N. J., Sharada, S. M., Sharma, S., Small, D. W., Sodt, A., Stein, T., Stück, D., Su, Y.C., Thom, A. J. W., Tsuchimochi, T., Vanovschi, V., Vogt, L., Vydrov, O., Wang, T., Watson, M. A., Wenzel, J., White, A., Williams, C. F., Yang, J., Yeganeh, S., Yost, S. R., You, Z.Q., Zhang, I. Y., Zhang, X., Zhao, Y., Brooks, B. R., Chan, G. K. L., Chipman, D. M., Cramer, C. J., Goddard, W. A., Gordon, M. S., Hehre, W. J., Klamt, A., Schaefer, H. F., Schmidt, M. W., Sherrill, C. D., Truhlar, D. G., Warshel, A., Xu, X., Aspuru-Guzik, A., Baer, R., Bell, A. T., Besley, N. A., Chai, J.-D., Dreuw, A., Dunietz, B. D., Furlani, T. R., Gwaltney, S. R., Hsu, C.-P., Jung, Y., Kong, J., Lambrecht, D. S., Liang, W., Ochsenfeld, C., Rassolov, V. A., Slipchenko, L. V., Subotnik, J. E., Van Voorhis, T., Herbert, J. M., Krylov, A. I., Gill, P. M. W., and Head-Gordon, M.: Advances in molecular quantum chemistry contained in the Q-Chem 4 program package, Mol. Phys., 113, 184-215, doi:10.1080/00268976.2014.952696, 2015.

Shepson, P. B. and Heicklen, J.: The wavelength and pressure dependence of the photolysis of propionaldehyde in air, J. Photochem., 19, 215-227, doi:10.1016/0047-2670(82)80024-5, 1982.

Shepson, P. B., Bottenheim, J. W., Hastie, D. R., and Venkatram, A.: Determination of the relative ozone and PAN deposition velocities at night, Geophys. Res. Lett., 19, 1121-1124, doi:10.1029/92GL01118, 1992.

Sprengnether, M., Demerjian, K. L., Donahue, N. M., and Anderson, J. G.: Product analysis of the $\mathrm{OH}$ oxidation of isoprene and 1,3-butadiene in the presence of NO, J. Geophys. Res., 107, ACH 8-1-ACH 8-13, doi:10.1029/2001jd000716, 2002.

Starn, T. K., Shepson, P. B., Bertman, S. B., Riemer, D. D., Zika, R. G., and Olszyna, K.: Nighttime isoprene chemistry at an urbanimpacted forest site, J. Geophys. Res.-Atmos., 103, 22437 22447, doi:10.1029/98JD01201, 1998.

Su, L., Patton, E. G., Vilà-Guerau de Arellano, J., Guenther, A. B., Kaser, L., Yuan, B., Xiong, F., Shepson, P. B., Zhang, L., Miller, D. O., Brune, W. H., Baumann, K., Edgerton, E., Weinheimer, A., and Mak, J. E.: Understanding isoprene photo-oxidation using observations and modelling over a subtropical forest in the Southeast US, Atmos. Chem. Phys. Discuss., 15, 31621-31663, doi:10.5194/acpd-15-31621-2015, 2015.

Suarez-Bertoa, R., Picquet-Varrault, B., Tamas, W., Pangui, E., and Doussin, J. F.: Atmospheric fate of a series of carbonyl nitrates: 
photolysis frequencies and $\mathrm{OH}-$ oxidation rate constants, Environ. Sci. Technol., 46, 12502-12509, doi:10.1021/es302613x, 2012.

Treacy, J., Hag, M. E., O'Farrell, D., and Sidebottom, H.: Reactions of Ozone with Unsaturated Organic Compounds, Berichte der Bunsengesellschaft für physikalische Chemie, 96, 422-427, doi:10.1002/bbpc.19920960337, 1992.

Tuazon, E. C. and Atkinson, R.: A product study of the gas-phase reaction of Isoprene with the $\mathrm{OH}$ radical in the presence of $\mathrm{NO}_{x}$, Int. J. Chem. Kinet., 22, 1221-1236, doi:10.1002/kin.550221202, 1990.

Tuazon, E. C., Atkinson, R., Mac Leod, H., Biermann, H. W., Winer, A. M., Carter, W. P. L., and Pitts, J. N.: Yields of glyoxal and methylglyoxal from the nitrogen oxide $\left(\mathrm{NO}_{x}\right)$-air photooxidations of toluene and m- and p-xylene, Environ. Sci. Technol., 18, 981-984, doi:10.1021/es00130a017, 1984.

Vingarzan, R.: A review of surface ozone background levels and trends, Atmos. Environ., 38, 3431-3442, doi:10.1016/j.atmosenv.2004.03.030, 2004.

Wang, X., Wang, T., Yan, C., Tham, Y. J., Xue, L., Xu, Z., and Zha, Q.: Large daytime signals of $\mathrm{N}_{2} \mathrm{O}_{5}$ and $\mathrm{NO}_{3}$ inferred at $62 \mathrm{amu}$ in a TD-CIMS: chemical interference or a real atmospheric phenomenon?, Atmos. Meas. Tech., 7, 1-12, doi:10.5194/amt-7-12014, 2014.

Wiberg, K. B., Hadad, C. M., Rablen, P. R., and Cioslowski, J.: Substituent effects. 4. Nature of substituent effects at carbonyl groups, J. Am. Chem. Soc., 114, 8644-8654, doi:10.1021/ja00048a044, 1992.
Wu, S., Mickley, L. J., Jacob, D. J., Logan, J. A., Yantosca, R. M., and Rind, D.: Why are there large differences between models in global budgets of tropospheric ozone?, J. Geophys. Res.-Atmos., 112, D05302, doi:10.1029/2006JD007801, 2007.

Xie, Y., Paulot, F., Carter, W. P. L., Nolte, C. G., Luecken, D. J., Hutzell, W. T., Wennberg, P. O., Cohen, R. C., and Pinder, R. W.: Understanding the impact of recent advances in isoprene photooxidation on simulations of regional air quality, Atmos. Chem. Phys., 13, 8439-8455, doi:10.5194/acp-13-8439-2013, 2013.

Xiong, F., McAvey, K. M., Pratt, K. A., Groff, C. J., Hostetler, M. A., Lipton, M. A., Starn, T. K., Seeley, J. V., Bertman, S. B., Teng, A. P., Crounse, J. D., Nguyen, T. B., Wennberg, P. O., Misztal, P. K., Goldstein, A. H., Guenther, A. B., Koss, A. R., Olson, K. F., de Gouw, J. A., Baumann, K., Edgerton, E. S., Feiner, P. A., Zhang, L., Miller, D. O., Brune, W. H., and Shepson, P. B.: Observation of isoprene hydroxynitrates in the southeastern United States and implications for the fate of $\mathrm{NO}_{x}$, Atmos. Chem. Phys., 15, 11257-11272, doi:10.5194/acp-15-11257-2015, 2015.

Zellner, R. and Lorenz, K.: Laser photolysis/resonance fluorescence study of the rate constants for the reactions of hydroxyl radicals with ethene and propene, J. Phys. Chem., 88, 984-989, doi:10.1021/j150649a028, 1984. 